\title{
p38 MAPK regulates steroidogenesis through transcriptional repression of STAR gene
}

\author{
Syed Kashif Zaidi ${ }^{1,2,+}$, Wen-Jun Shen ${ }^{1,2}$, Stefanie Bittner ${ }^{1}$, Alex Bittner ${ }^{1}$, \\ Mark P McLean ${ }^{4}$, Jiahuai Han ${ }^{5}$, Roger J Davis ${ }^{6}$, Fredric B Kraemer, ${ }^{1,2}$ and \\ Salman Azhar ${ }^{1,3}$ \\ ${ }^{1}$ Geriatric Research, Education and Clinical Center (GRECC-182B), VA Palo Alto Health Care System, 3801 Miranda \\ Avenue, Palo Alto, California 94304, USA \\ ${ }^{2}$ Division of Endocrinology ${ }^{3}$ Division of Gastroenterology and Hepatology, Stanford University, Stanford, \\ California 94305, USA \\ ${ }^{4}$ Department of Obstetrics and Gynecology, University of South Florida College of Medicine, Tampa, \\ Florida 33612, USA \\ ${ }^{5}$ State Key Laboratory of Cellular Stress Biology, School of Life Sciences, Xiamen University, Xiamen, \\ Fujian 361005, China \\ ${ }^{6}$ Program in Molecular Medicine, University of Massachusetts Medical School, Worcester, Massachusetts 01605, USA \\ 'S K Zaidi is now at Center of Excellence in Genomic Research, King Abdulaziz University, Kingdom of Saudi Arabia, \\ Jeddah 21589, Saudi Arabia
}

Correspondence should be addressed to S Azhar Email salman.azhar@va.gov

\begin{abstract}
STAR/StarD1, part of a protein complex, mediates the transport of cholesterol from the outer to inner mitochondrial membrane, which is the rate-limiting step for steroidogenesis, and where steroid hormone synthesis begins. Herein, we examined the role of oxidant-sensitive p38 MAPKs in the regulation of STAR gene transcription, using model steroidogenic cell lines. Our data indicate that oxidant activation of p38 MAPK exhibits a negative regulatory role in the induction of functional expression of STAR, as evidenced by enhanced induction of STAR (mRNA/protein) expression and increased steroidogenesis during pharmacological inhibition of $\mathrm{p} 38$ MAPK or in cells with increased transient overexpression of a dominantnegative $(\mathrm{dn})$ form of $\mathrm{p} 38$ MAPK $\alpha$ or $\mathrm{p} 38$ MAPK $\beta$. Studies with rat Star-promoter demonstrated that overexpression of p38 MAPK $\alpha-w t,-\beta$, or $-\gamma$ significantly reduced both basal and CAMP-sensitive promoter activity. In contrast, overexpression of p38 MAPK $\alpha$-dn, $-\beta$, or $-\gamma$ enhanced the Star promoter activity under basal conditions and in response to CAMP stimulation. Use of various constitutively active and dn constructs and designer knock-out cell lines demonstrated that MKK3 and MKK6, the upstream activators of p38 MAPKs, play a role in p38 MAPK $\alpha$-mediated inhibition of Star promoter activity. In addition, our studies raised the possibility of CREB being a potential target of the p38 MAPK inhibitory effect on Star promoter activity. Collectively, these data provide novel mechanistic information about how oxidant-sensitive p38 MAPKs, particularly p38 MAPK $\alpha$, contribute to the negative regulation of Star gene expression and inhibit steroidogenesis.
\end{abstract}

\section{Key Words}

- steroid hormones

- cAMP

- oxidative stress

- Y1 cells

- MLTC-1 cells

- CREB

- steroids
Journal of Molecular Endocrinology (2014) 53, 1-16 http://jme.endocrinology-journals.org DOI: 10.1530/JME-13-0287
() 2014 Society for Endocrinology Printed in Great Britain
Published by Bioscientifica Ltd 


\section{Introduction}

Extensive experimental evidence now indicates that aging in humans and animal models is associated with a general decline in steroid hormone production (Zaidi et al. 2012). Similarly, a number of in vitro studies have clearly shown that isolated adrenocortical cells and testicular Leydig cells (Zaidi et al. 2012) of older rats of several different strains synthesize and secrete less steroid hormone in response to tropic hormone or its second messenger, cAMP, than do cells from younger animals. These changes in steroid hormone production and secretion do not appear to be a function of reduced tropic hormone signaling or a defect in steroid hormone-synthesizing enzymes.

Previous work from this laboratory has shown that an adequate amount of cholesterol is not available to the adrenal (adrenocortical cells) and testis (Leydig cells) in aging rats (Popplewell \& Azhar 1987, Liao et al. 1993, Sun et al. 2008, Zaidi et al. 2012) for the initial and rate-limiting step in steroid biosynthesis, i.e. translocation of cholesterol from the outer mitochondrial membrane (OMM) to the P450 side-chain cleavage enzyme (P450scc/Cyp11A1), which is localized in the matrix side of the inner mitochondrial membrane (IMM) and converts cholesterol to pregnenolone, the precursor of all steroid hormones (Stocco \& Clark 1996, Stocco 2001, Hu et al. 2010, Miller \& Bose 2011). This aging-induced attenuation of cholesterol transport to mitochondria is not due to a loss of cellular cholesterol stores, but results from the downregulation of STAR (Leers-Sucheta et al. 1999, Luo et al. 2001, Wang et al. 2005, Sun et al. 2008) and peripheral-type benzodiazepine receptor or translocator protein (TSPO; Culty et al. 2002, Sun et al. 2008). These components of the steroidogenic machinery (Stocco \& Clark 1996, Stocco 2001) probably function in concert (Liu et al. 2006) to facilitate ratelimiting cholesterol transport from the OMM to the IMM (Hu et al. 2010, Miller \& Bose 2011). Although various cellular and molecular mechanisms controlling this aging defect have not been definitely identified, excessive reactive oxygen species (ROS) production (Azhar et al. 1995, Cao et al. 2004, Abidi et al. 2008a,b, Zaidi et al. 2012) and ROS-induced oxidative damage to STAR have been suggested as a potential mechanism for impaired cholesterol transport to the IMM for steroid production during aging.

p38 MAPKs are members of the MAPK family that are activated by a variety of environmental stresses and inflammatory cytokines (Roux \& Blenis 2004, Coulthard et al. 2009, Cuadrado \& Nebreda 2010, Remy et al. 2010, Corrêa \& Eales 2012). The four members of the p38 MAPK isoform family are p38 MAPK $\alpha$ (MAPK14), p38 MAPK $\beta$
(SAPK2b), p38 MAPK $\gamma$ (SAPK3, ERK6, or MAPK14), and

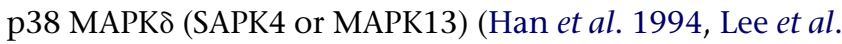
1994, Rouse et al. 1994, Coulthard et al. 2009, Cuadrado \& Nebreda 2010, Remy et al. 2010). These isoforms differ in their organ/tissue distribution, regulation of kinase activation and subsequent phosphorylation of downstream substrates, kinases or transcription factors, and sensitivity to pharmacological inhibition by pyridinyl imidazole molecules such as SB203580 and SB202190 (Bain et al. 2007, Coulthard et al. 2009, Cuadrado \& Nebreda 2010, Remy et al. 2010). Various forms of cellular stress, including oxidative stress, u.v. irradiation, hypoxia, and ischemia, as well as inflammatory cytokines, stimulate the activity of p38 MAPKs (Coulthard et al. 2009, Cuadrado \& Nebreda 2010, Remy et al. 2010) by dual phosphorylation of $\mathrm{Thr}^{180}$ and $\mathrm{Tyr}^{182}$ in a Thr-Gly-Tyr motif. This phosphorylation is mediated by upstream MAPKs (MAPKKs), MKK3 and MKK6 (Derijard et al. 1995, Raingeaud et al. 1995, 1996, Han et al. 1996), which are in turn activated by several different and overlapping sets of MAPKKKs or MEKKs (Coulthard et al. 2009, Cuadrado \& Nebreda 2010, Remy et al. 2010).

Recently, we have shown that aging leads to increased activation of p38 MAPK $\alpha$ in rat adrenocortical cells (Abidi etal. 2008a). This effect appears to be specific for $\mathrm{p} 38 \mathrm{MAPK} \alpha$, as the expression of neither ERK1/2 nor JNK1/2 was altered during aging (Abidi et al. 2008a). We also showed that the use of p38 MAPK inhibitors (SB203580 and SB202190) and antioxidants (NAC and MnTMPyP) partially restored the steroidogenesis in adrenal cells from old animals, indicating that the p38 MAPK signaling cascade facilitates the inhibitory actions of excessive oxidative insult on adrenal steroid hormone production caused by aging (Abidi et al. $2008 a$ ). These results were further complemented by in vitro studies using a mouse adrenocortical tumor cell line, Y-1, showing that activated p38 MAPKs mediate oxidant (excessive oxidative stress)-induced inhibition of steroid production (Abidi et al. 2008b).

In the present study, we sought to determine molecular mechanisms by which the oxidant-sensitive p38 MAPK inhibits cAMP-induced steroidogenesis. Herein, we show that the inhibitory effect of p38 MAPK on cAMP-induced steroidogenesis in model steroidogenic cell lines is due to a decrease in StAR expression and its promoter activity. Furthermore, expression and functional activity of cAMP response-element binding protein (CREB), a mediator of tropic hormone/cAMPstimulated STAR gene transcription, is also sensitive to the

Published by Bioscientifica Ltd. 
inhibitory actions of p38 MAPK. The current study describes the molecular events responsible for the p38 MAPK-mediated negative regulation of STAR gene transcription and inhibition of steroidogenesis.

\section{Materials and methods}

\section{Reagents and antibodies}

$N^{6}, 2$ '-O-dibutyryl cAMP (Bt $\left.{ }_{2} \mathrm{CAMP}\right), \quad \mathrm{SB} 203580$, SB 202190, xanthine, xanthine oxidase (XO), microbial, fatty acid-free BSA, hydrogen peroxide, and monoclonal Anti-FLAG M2 antibody and mouse monoclonal antiactin antibody were obtained from Sigma-Aldrich. 4-Hydroxy-2-nonenal (HNE) was purchased from Cayman Chemical Co. (Ann Arbor, MI, USA). The NEP-PER Nuclear Protein Extraction Kit, and Promega Dual-Luciferase Reporter Kit (E1980) were purchased from Thermo Fisher Scientific (Rockford, IL) and Promega Corporation respectively. Anti-phospho-CREB (Ser ${ }^{133}$ ), anti-CREB, pan antip38 MAPK, and anti-phospho-p38 MAPK $\left(\mathrm{Thr}^{180} / \mathrm{Tyr}^{182}\right)$ antibodies that detect endogenous levels of total and phosphorylated (activated) forms of p38 MAPK $\alpha, \beta$, or $\gamma$ protein, respectively, were obtained from Cell Signaling Technology, Inc. (Danvers, MA, USA). IRDye 800CW goat anti-rabbit and IRDye 680LT goat anti-mouse secondary antibodies were purchased from LI-COR Corporate (Lincoln, NE, USA). SYBR Green Master Mix and Lipofectamine 2000 were supplied by Applied Biosystems and Invitrogen (Life Technologies) respectively.

\section{Plasmids}

The generation of Rat Star promoter-pGL3 constructs p-1862-luc, p-1413-luc, p-998-luc, p-545-luc, and p-342luc has been described in an earlier publication (Sandhoff et al. 1998). The mouse Star promoter constructs, pGL3 (p-966-luc; Manna et al. 2002), were kindly supplied by Dr Douglas Stocco (Texas Tech University Health Sciences Center, Lubbock, TX, USA). The pcDNA3-Flag-tagged-p38 MAPK $\alpha$-wt, p38 MAPK $\beta$-wt, p38 MAPK $\gamma$-wt, p38 MAPK $\delta-$ wt, p38 MAPKa/AF-dn (dominant negative) p38 MAPK$\beta / A F-d n, p 38$ MAPK $\gamma / A F-d n$, and p38 MAPK $\delta / A F-d n$ constructs used here have been described previously (Pramanik et al. 2003). The dn forms (AF) of human p38 MAPK $\alpha$, p38 MAPK $\beta$, p38 MAPK $\gamma$, and p38 MAPKס cDNA constructs were created by substituting $\mathrm{Thr}^{188}$ with Ala and $\mathrm{Tyr}^{190}$ with Phe in the TGY dual phosphorylation site. Because AF mutant proteins cannot be phosphorylated, they act as dn proteins and interfere with the functions of their respective p38 MAPKs. The pcDNA3-Flag-tagged MKK3-wt, MKK3 (AA)-dn, MKK3 (EE)-ca (constitutively active), MKK6-wt, MKK6 (AA)-dn, and MKK6 (EE)-ca expression constructs used here were generated as reported previously (Han et al. 1996, Raingeaud et al. 1996); ca MKK3 (EE)-ca and dn MKK3 (AA)-dn were constructed by replacing $\operatorname{Ser}^{189}$ and $\mathrm{Thr}^{193}$ with Glu and Ala residues respectively. Likewise, ca MKK6 (EE)-ca and dn MKK6 (AA)-dn were constructed by replacing $\mathrm{Ser}^{207}$ and $\mathrm{Thr}^{211}$ with Glu and Ala residues respectively. HA-MKK6-p38 MAPK $\alpha$-ca, HA-MKK6-p38 MAPK $\gamma$-ca, HA-MKK6-p38 $\alpha /$ AGF-dn, and HA-MKK6-p38 $\gamma /$ AGF-dn fusion constructs were kindly provided by Dr Guan Chen (University of Wisconsin, Madison, WI, USA). RSV-CREB plasmid was purchased from Addgene (Cambridge, MA, USA). CRE-Reporter (luc) and activator protein 1 (AP1) (TPAresponse element (TRE)) Reporter (luc) kits were obtained from Qiagen-SA Biosciences (Valencia, CA, USA). Both CRE-Reporter (luc) and AP1 (TRE) Reporter (luc) are inducible reporter constructs that encode a firefly luciferase gene under the control of a basal promoter element (TATA box) joined to tandem six repeats $(6 \times)$ of CRE and AP1/TRE transcriptional response elements respectively.

\section{Cell culture}

Mouse Y-1 adrenocortical tumor cells, mouse MLTC-1 testicular Leydig tumor cells, and human embryonic kidney-293 (HEK-293) cells were originally obtained from the American Type Culture Collection (ATCC) (Manassas, VA, USA). MLTC-1 cells were maintained in RPMI 1640 medium with 10\% fetal bovine serum (FBS), $100 \mu \mathrm{g} / \mathrm{ml}$ streptomycin, 100 units/ml penicillin, and $1 \%$ L-glutamine in a humidified atmosphere of $5 \% \mathrm{CO}_{2}$ at $37^{\circ} \mathrm{C}$. Y-1 cells were maintained at $37^{\circ} \mathrm{C}$ in a humidified $5 \% \mathrm{CO}_{2}$ atmosphere in Ham's F-10 medium supplemented with $2.5 \%$ FBS, $12.5 \%$ horse serum, $100 \mu \mathrm{g} / \mathrm{ml}$ streptomycin, and 100 units/ml penicillin. MKK3/6 wt, $\mathrm{MKK}^{-1-}, \mathrm{MKK}^{-1-}$, and MKK3/6 double knock-out (DKO) mouse embryonic fibroblasts (MEFs) (Brancho et al. 2003) were maintained in DMEM containing $10 \% \mathrm{FBS}, 100 \mu \mathrm{g} / \mathrm{ml}$ streptomycin, and 100 units $/ \mathrm{ml}$ penicillin at $37^{\circ} \mathrm{C}$ with $5 \% \mathrm{CO}_{2}$.

\section{Transfections and luciferase assays}

MLTC-1 (or other cell types such as Y1, and MEFs, MKK3/6 wt, $\mathrm{MKK}^{-1-}, \mathrm{MKK}^{-1-}$, and MKK3/6 ${ }^{-1-}$ ) cells were seeded at a density of $1 \times 10^{5}$ cells/well in a 12-well plate containing a cell-type-specific culture medium as

Published by Bioscientifica Ltd. 
described earlier. After overnight incubation, cells were transiently transfected with a rat p-1862 Star-Luc (firefly luciferase) construct $(1 \mu \mathrm{g}) \pm$ native p38 MAPK $\alpha$ (wt) $(1 \mu \mathrm{g})$ or dn p38 MAPK $\alpha(1 \mu \mathrm{g})$ using Lipofectamine 2000 according to the manufacturer's instructions (Invitrogen, Life Technologies). A control reporter construct containing Renilla luciferase (Rluc, pRL-TK) (50 ng) was co-transfected for normalization of transfection efficiency. In some cases, MLTC- 1 cells were transfected with rat p-1862 Star-Luc (firefly luciferase) construct $(1 \mu \mathrm{g})+$ pRLTK (50 ng) and \pm p38 MAPK $\beta$-wt $(1 \mu \mathrm{g}), \pm$ p38 MAPK $\beta$ $\mathrm{dn}, \pm$ p38 MAPK $\gamma$-wt $(1 \mu \mathrm{g}), \pm$ p38 MAPK $\gamma$-dn $(1 \mu \mathrm{g})$, \pm p38 MAPK $\delta$-wt, \pm p38 MAPK $\delta$-dn, \pm MKK6-p38 MAPK $\alpha-c a, \pm$ MKK6-p38 MAPK $\alpha-d n, \pm$ MKK6-p38 MAPK $\gamma$-ca, \pm MKK6-p38 MAPK $\gamma$-dn, \pm MKK3-wt, \pm MKK3-dn (AA), \pm MKK3-ca (EE), \pm MKK6-wt, \pm MKK6-dn (AA), or \pm MKK6-ca (EE). In each case, total DNA concentration was kept constant to $3 \mu \mathrm{g}$ with the addition of inert pcDNA3. After $48 \mathrm{~h}$, cells were incubated with or without $\mathrm{Bt}_{2} \mathrm{CAMP}$ for $5 \mathrm{~h}$, washed, harvested using cell lysis buffer (Promega Corporation), and subsequently assayed for both firefly and Renilla luciferase activities using the Promega Dual-Luciferase Reporter Kit (E1980) and a SpectraMax L luminescence Microplate Reader (Molecular Devices, Sunnyvale, CA, USA) or GloMax20/20 Single-Tube Luminometer (Promega Corporation). Firefly luciferase activities were normalized to Renilla luciferase reporter activities and shown as -fold induction compared with control (empty vector). The results shown are the average of triplicate determinations with the error bars representing s.E.M. All the experiments were independently repeated at least two to three times.

In other assays, MLTC-1 cells were transfected with CRE-luc (firefly luciferase) + Renilla luciferase (Rluc, pRL-TK), \pm CREB, or \pm CREB + p38 MAPK $\alpha$-wt or p38 MAPK $\alpha$-dn, for $48 \mathrm{~h}$. At the end of incubation, washed dishes were further incubated with or without $\mathrm{Bt}_{2} \mathrm{CAMP}$ followed by measurement of firefly and Renilla luciferase activities. Likewise, MLTC-1 cells were transfected with AP1/TRE-luc (firefly luciferase) + Renilla luciferase (Rluc, pRL-TK) \pm p38 MAPK $\alpha$ wt or p38 MAPK $\alpha$-dn and, after $48 \mathrm{~h}$, dishes were further incubated with or without AP1/TRE activator TPA (10 nM) for $30 \mathrm{~min}$. The cell lysates were then quantified for firefly and Renilla luciferase activities.

\section{Transfection of MLTC-1 cells with p38 MAPK constructs and measurement of steroid (progesterone) secretion}

MLTC- 1 cells were seeded at a density of $1 \times 10^{5}$ cells/well in a 12-well plate containing RPMI 1640 medium supplemented with $10 \%$ FBS, $100 \mu \mathrm{g} / \mathrm{ml}$ streptomycin, 100 units $/ \mathrm{ml}$ penicillin, and $1 \%$ L-glutamine (under 5\% $\mathrm{CO}_{2}$ at $37^{\circ} \mathrm{C}$ ) for $24 \mathrm{~h}$ before transfection. The cells were transfected with native wt-p38 MAPK $\alpha(1 \mu \mathrm{g})$ and/or dn-p38 MAPK $\alpha(1 \mu \mathrm{g})$ or pcDNA3 $(3 \mu \mathrm{g})$ using Lipofectamine 2000 as recommended by the manufacturer (Invitrogen, Life Technologies). In each case, the total amount of plasmid $(3 \mu \mathrm{g})$ was kept the same with the addition of inert pcDNA3. Forty-eight hours after transfection, the medium was replaced with a fresh medium and the cells (triplicate wells) were treated with $\pm \mathrm{Bt}_{2} \mathrm{CAMP}(2.5 \mathrm{mM})$ and incubations continued for an additional $5 \mathrm{~h}$. At the end of incubation, media were aspirated and stored frozen until analyzed for secreted progesterone content by RIA as described earlier (Reaven et al. 1995). The cells were washed once with PBS and then processed for the determination of Star/StarD1 mRNA expression by quantitative RT-PCR as described below.

\section{Quantitative real-time PCR}

Total RNA from MLTC-1 and Y-1 cells was isolated by using TRIzol reagent (Invitrogen) according to the manufacturer's instructions. RNA concentration and purity were quantified using a NanoDrop Spectrophotometer (Thermo Scientific). Samples $(2 \mu \mathrm{g})$ RNA were reverse transcribed to cDNA at $42^{\circ} \mathrm{C}$ for $1 \mathrm{~h}$ using SuperScript II reverse transcriptase (Invitrogen) and oligo(dT) and random hexamers. Quantitative real-time PCR (qRT-PCR) was carried out using specific primers (Table 1) and amplified using SYBR Select Master Mix for CFX (Applied Biosystems) in an ABI Prism 7900HT Sequence Detection System (Applied Biosystems). The results are presented as relative mRNA expression levels calculated using the formula $2^{-\Delta \Delta C \mathrm{~T}}$, where $\Delta \Delta C \mathrm{~T}=\Delta C \mathrm{~T}_{\text {target }}-\Delta C \mathrm{~T}_{\text {reference }}$ with $36 \mathrm{~B} 4$ (60) acidic ribosomal protein $\mathrm{P0}$ ) as the reference gene.

\section{Western blotting analysis}

The cells were washed with PBS and then harvested in RIPA buffer, containing a Complete Protease Inhibitor Cocktail and PhosSTOP phosphatase inhibitor cocktail (both from Roche Diagnostics) directly to plates and scraping into tubes. The cells were briefly sonicated, and centrifuged for $5 \mathrm{~min}$. The protein concentrations of the lysates were measured using the Pierce BCA Protein Assay Reagent Kit (Thermo Fischer Scientific, Rockford, IL, USA). Proteins from cell lysates $(20 \mu \mathrm{g})$ were resolved on a precast 4-20\% gradient SDS-PAGE and electro-transferred onto

Published by Bioscientifica Ltd 
Table 1 Oligonucleotide sequences used in quantitative real-time PCR (qRT-PCR) analysis

Gene
m-Star/StarD1
m-StarD2
m-StarD3
m-StarD4
m-StarD5
m-StarD6
m-StarD7
m-StarD10
m-p38 MAPK $\alpha$
m-p38 MAPK $\beta$
m-p38 MAPK $\gamma$
m-p38 MAPK 8
m-Cyclophilin
m-36B4

\begin{tabular}{l} 
Forward \\
\hline 5'-GGATTAAGGCACCAAGCTGT-3' $^{\prime}$ \\
5'-TGTGCTGAACTCCAGAAACC-3' $^{\prime}$ 5'-CCTGCTCTTCATCTCCCTTC-3' \\
5'-TCCTGTGGTGTGAGTGTTGA-3' $^{\prime}$ \\
5'-GGGAATCTGTACCGAGGAGA-3' \\
5'-CACAGTTCGCACTCCTCTGT-3' \\
5'-ATGTTCGGCGGTATAGTGTG-3' \\
5'-CTGGAACCTGACCTACAGCA-3' \\
5'-CCCCAGAGATCATGCTGAAT-3' \\
5'-ATGTAGCGGTGAACGAGGA-3' \\
5'-GAGACTTGAAGCCTGGCAAC-3' \\
5'-CGCCACACAGACACTGAGA-3' \\
5'-TGGAGAGCACCAAGACAGACA-3' \\
5'-CCTGAAGTGCTCGACATCAC-3'
\end{tabular}

\section{Reverse}

5'-CCAGTTGAGAACCAAGCAGA-3'

5'-ATAAAGTCCACTTGGCTGGTC-3'

$5^{\prime}$-CTCCTGCTCCAAGTTCTTCC- $3^{\prime}$

5'-TGGCTTGGACTGTCTTTGAG-3'

5'-AACTGGCTTTATGCAATCCC-3'

5'-CTCTGCAGGAACAAACTCCA-3'

5'-GGATAACCATTTGGGATTCG-3'

5'-CCATCCGACACTTGATCTTG-3'

5'-ACAACGTTCTTCCGGTCAAC- $3^{\prime}$

5'-CCACATATCCGGTCATCTCC-3'

5'-CCGGGTTACCACATATCCTG-3'

5'-ATGATGCAACCAACAGACC-3'

5'-TGCCGGAGTCGACAATGAT-3'

5'-CGATCTGCAGACACACACTG-3' a Hybond nitrocellulose membrane (Amersham, GE Healthcare, Piscataway, NJ, USA). The membranes were blocked, incubated with anti-p38 MAPK, anti-phosphop38 MAPK, anti-CREB, anti-phospho-CREB, and mouse anti- $\beta$-actin antibodies, washed, and incubated with IRDye $800 \mathrm{CW}$ goat anti-rabbit and IRDye 680LT goat anti-mouse secondary antibodies. The membrane blots were then imaged using an ODYSSEY Infrared Imaging System (LI-COR Biosciences). Quantification of bands was made with the analysis software provided with the imaging system.

\section{Statistical analysis}

Data are presented as mean \pm s.E.M. Statistical analyses were performed using ANOVA followed by the Bonferroni's post test using GraphPad Prism Software, Prism 4 (GraphPad Software, Inc., San Diego, CA, USA). A P value of $<0.05$ was considered statistically significant. All experiments were performed independently at least three times.

\section{Results}

Effect of $\mathrm{Bt}_{2} \mathrm{CAMP}$ stimulation on mRNA levels of Star and Star-related lipid transfer proteins in MLTC-1 and Y-1 cells

The human and mouse genomes each contain 15 genes encoding Star-related lipid transfer (START) domaincontaining proteins (STARD; Soccio \& Breslow 2003). STAR (STARD1), the prototype of the STARD family of proteins, plays an essential role in moving cholesterol substrate to the IMM of steroidogenic cells of the adrenal gland and gonads, where the first committed step in steroidogenesis occurs (Stocco 2001, Miller \& Bose 2011).
Herein, we assessed the mRNA levels of Star (StarD1) (subsequently referred to as Star) and other StarD family members under basal conditions and in response to cAMP stimulation in two steroidogenic cell lines, MLTC-1 and Y-1. Total RNA samples were analyzed for Star, StarD2, 3, 4, $5,6,7$, and 10 mRNA expression by qRT-PCR. The results shown in Fig. 1 indicate that Star mRNA is most abundantly expressed in both MLTC- 1 and Y-1 cells and that $\mathrm{Bt}_{2} \mathrm{CAMP}$ (a cell-permeable analog of cAMP) stimulation further increased its mRNA levels by four- to fivefold in both cell types. Relatively low mRNA expression of StarD4 and StarD7 was also detected in MLTC-1 cells, and $\mathrm{Bt}_{2} \mathrm{cAMP}(2.5 \mathrm{mM})$ treatment of these cells enhanced StarD4 expression by four- to fivefold (Fig. 1). In Y-1 cells, low, but significant, mRNA expression was noted for StarD4, StarD5, and StarD7, although their levels were not affected by $\mathrm{Bt}_{2} \mathrm{cAMP}$ stimulation. The higher levels of mRNA expression of STAR protein compared with other STARD proteins in MLTC- 1 and Y-1 cells are consistent with its critical role in the regulation of steroidogenesis.

\section{Expression of endogenous mRNA levels of p38 MAPK isoforms in MLTC-1 and Y-1 cells}

Using qRT-PCR, we next determined the relative mRNA expression levels of each of the four p38 MAPK isoforms in MLTC-1 and Y-1 cells (Fig. 2). p38 MAPK $\alpha$ expression was most abundant in both cell types; only low levels of p38 MAPK $\beta$ were detected in Y-1 cells, while its mRNA levels were roughly $40 \%$ of the levels of p38 MAPK $\alpha$ in MLTC-1 cells (Fig. 2). Low levels of p38 MAPK $\gamma$ mRNA were also detected in Y-1 cells as well as in MLTC-1 cells. The expression of p38 MAPK $\delta$, however, was barely detectable in MLTC-1, and Y-1 cells showed only low expression

Published by Bioscientifica Ltd. 


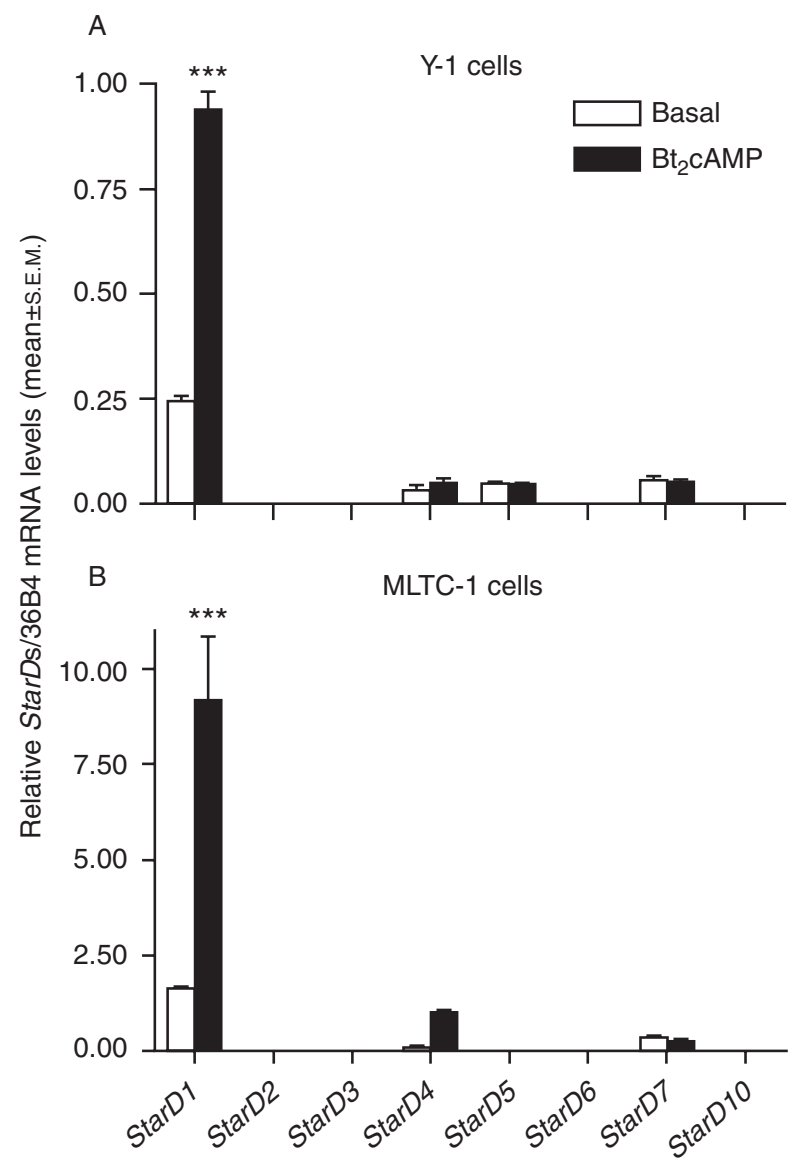

Figure 1

qRT-PCR analysis of StarD1/Star, StarD2, StarD3, StarD4, StarD5, StarD6, StarD7, and StarD10 mRNA levels in mouse $\mathrm{Y}-1$ adrenal cells and mouse Leydig tumor cells, MLTC-1, treated with or without $\mathrm{Bt}_{2} \mathrm{CAMP}(2.5 \mathrm{mM})$ for $6 \mathrm{~h}$. Groups of RNA samples from Y-1 or MLTC-1 cells were analyzed by qRT-PCR as described in the 'Materials and methods' section. The levels of expression of StarD1/Star, StarD2, StarD3, StarD4, StarD5, StarD6, StarD7, and StarD10 mRNAs are shown. Expression of cyclophilin was used for normalization. (A) Y-1 cells and (B) MLTC-1 cells. Each value represents mean \pm s.E.M. of four separate determinations. ${ }^{* *} P<0.0001$ basal (control) vs $\mathrm{Bt}_{2}$ CAMP.

(Fig. 2). These results led us to conclude that p38 MAPK $\alpha$ is the predominant form in both cell types, but significant expression of $\mathrm{p} 38 \mathrm{MAPK} \beta$ and $\mathrm{p} 38 \mathrm{MAPK} \gamma$ was also detected in MLTC-1 and Y-1 cells respectively. Thus, most of the follow-up studies focused on the p38 MAPK $\alpha$ isoform.

\section{Effects of oxidants and $\mathrm{Bt}_{2} \mathrm{CAMP}$ on Star mRNA expression in steroidogenic cell lines}

To examine the effect of oxidants on Star mRNA expression, MLTC-1 and Y-1 cells were pre-exposed to xanthine/XO (X/XO; superoxide anion), hydrogen peroxide, lipid peroxidation product, HNE, or vehicle (control) for $1 \mathrm{~h}$, the dishes washed and treated or not treated a cell membrane-permeable cAMP analog, $\mathrm{Bt}_{2-}$ cAMP, for $5 \mathrm{~h}$. Total RNA was isolated and Star mRNA measured using qRT-PCR. When cells were treated for $5 \mathrm{~h}$, the results demonstrated that Star mRNA levels, as expected, increased threefold to fourfold following treatment with $2.5 \mathrm{mM} \mathrm{Bt}_{2} \mathrm{cAMP}$ compared with nontreatment control (Fig. 3). Treatment of cells with a superoxidegenerating system (X/XO), hydrogen peroxide, or a lipid peroxidation product, HNE, under basal conditions caused a significant reduction in Star mRNA levels in MLTC-1 and Y-1 cells, ranging from 30 to $80 \%$ (Fig. 3). Likewise, preexposure of cells to these three oxidants caused a variable, but significant, reduction in $\mathrm{Bt}_{2} \mathrm{cAMP}$-stimulated Star mRNA levels (Fig. 3). These results indicate that exposure of steroidogenic cells to different oxidants results in downregulation of StAR gene expression.

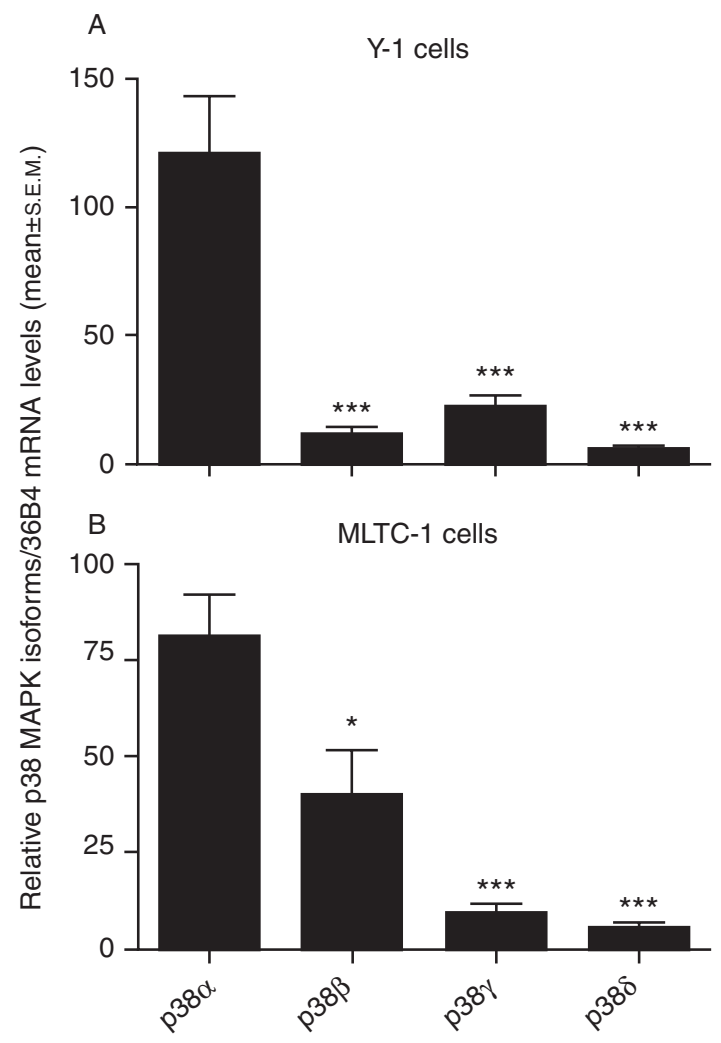

Figure 2

QRT-PCR analyses of p38 MAPK isoforms, p38 MAPK $\alpha$, p38 MAPK $\beta$, p38 MAPK $\gamma$, and p38 MAPK $\delta$ mRNA levels in cultured $Y-1$ and MLTC-1 cells. Groups of RNA samples from Y-1 or MLTC-1 cells were analyzed by qRT-PCR as described in the 'Materials and methods' section. The levels of expression of p38 MAPK $\alpha$, p38 MAPK $\beta$, p38 MAPK $\gamma$, and p38 MAPK $\delta$ mRNAs are shown. Expression of 36B4 was used for normalization. (A) Y-1 cells and (B) MLTC-1 cells. Each value represents mean \pm S.E.M. of four separate determinations. ${ }^{*} P<0.05$ p38 $\alpha$ vs p38 $\beta$ (MLTC- 1 ) and $* * * P<0.001$ p38 $\alpha$ vs $\mathrm{p} 38 \beta(\mathrm{Y}-1), \mathrm{p} 38 \gamma$ or $\mathrm{p} 38 \delta$.

Published by Bioscientifica Ltd. 


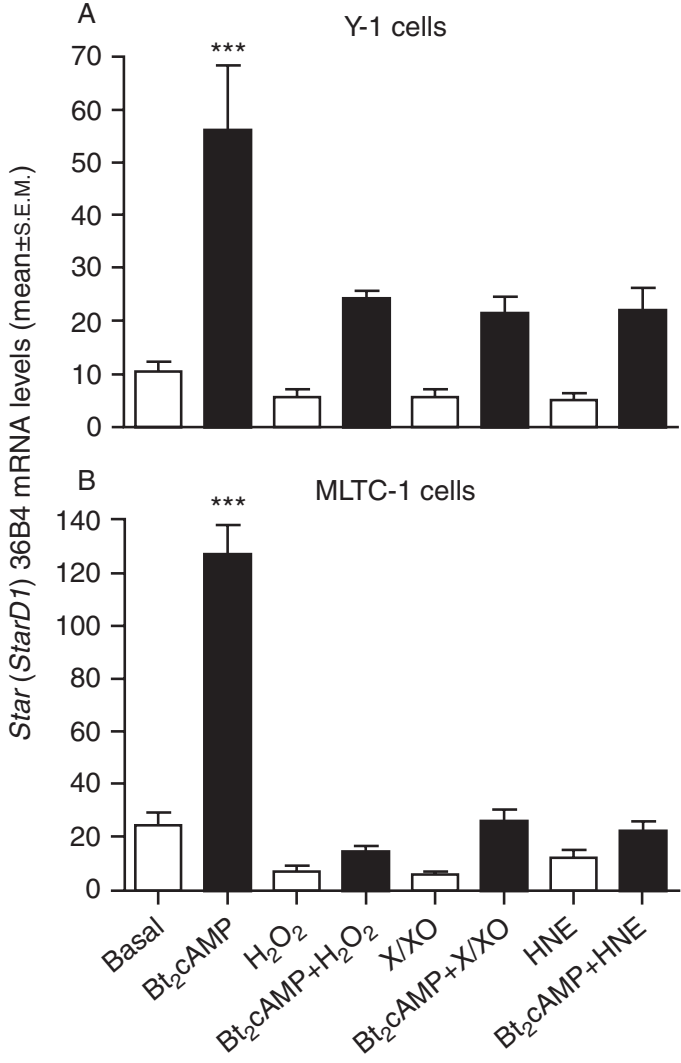

Figure 3

Exposure of $\mathrm{Y}-1$ cells (A) and MLTC-1 cells (B) to xanthine/xanthine oxidase $(\mathrm{X} / \mathrm{XO})$ generated superoxide anion $\left(\mathrm{O}_{2}^{-}\right)$or hydrogen peroxide $\left(\mathrm{H}_{2} \mathrm{O}_{2}\right)$ attenuates mRNA expression of Star/StarD1 both under basal conditions and in response to CAMP stimulation. Cultured $\mathrm{Y}-1$ and MLTC-1 cells were exposed to $\pm 0.1 \mathrm{mM}$ xanthine and $10 \mathrm{mU} / \mathrm{ml} \mathrm{XO}$ or $\pm 50 \mu \mathrm{M}$ hydrogen peroxide $\left(\mathrm{H}_{2} \mathrm{O}_{2}\right)$ for $1 \mathrm{~h}$. At the end of incubation, the dishes were washed and subsequently incubated with or without Bt 2 CAMP $(2.5 \mathrm{mM})$ for $5 \mathrm{~h}$, followed by isolation of total RNA and the quantification of the Star/StarD1 mRNA levels by qRT-PCR. Each value represents mean \pm s.E.M. of four separate determinations. $* * * P<0.0001$ basal (control) vs $\mathrm{Bt}_{2} \mathrm{CAMP}$.

\section{Oxidant activation of p38 MAPK negatively affects CAMP transcriptional regulation of Star}

The results described above indicate that oxidant exposure of steroidogenic cells results in downregulation of Star mRNA levels. As the p38 MAPK pathway has been implicated in mediating oxidative-stress-induced inhibition of steroid hormone synthesis (Abidi et al. $2008 a, b$ ), we investigated the role of p38 MAPK signaling in oxidant modulation of cAMP-mediated transcriptional regulation of STAR protein. MLTC-1 cells were transiently transfected with a construct containing the promoter region (-2862) of rat Star, a control reporter construct containing Renilla luciferase for normalization of transfection efficiency and with or without an expression plasmid encoding FLAG-p38 MAPK $\alpha$, and, after $48 \mathrm{~h}$, cells were exposed to vehicle (control), superoxide anion $\left(\mathrm{O}_{2}^{-}\right)$, $\mathrm{X} / \mathrm{XO}$, the generator of $\mathrm{O}_{2}^{-}$), $\mathrm{H}_{2} \mathrm{O}_{2}$, or HNE (a lipid peroxidation product) for an additional $60 \mathrm{~min}$. After extensive washing, cells were treated with $\pm \mathrm{Bt}_{2} \mathrm{cAMP}$ $(2.5 \mathrm{mM})$ for $3 \mathrm{~h}$, harvested and cell lysates analyzed for firefly and Renilla luciferase activities or subjected to western blotting analysis for the measurement of total and phosphorylated (activated) forms of p38 MAPK $\alpha$. As shown in Fig. 4A, short-term exposure of transfected cells to optimal doses of superoxide anion, $\mathrm{H}_{2} \mathrm{O}_{2}$, or $\mathrm{HNE}$ resulted in p38 MAPK $\alpha$ activation, as indicated by an increased level of phosphorylation at residues $\mathrm{Thr}^{180}$ and

A

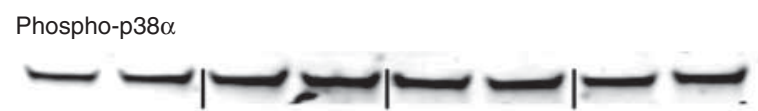

Total p38 $\alpha$

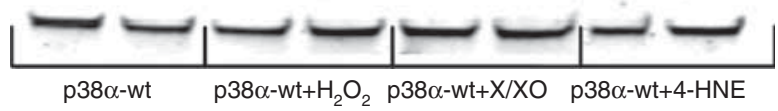

B

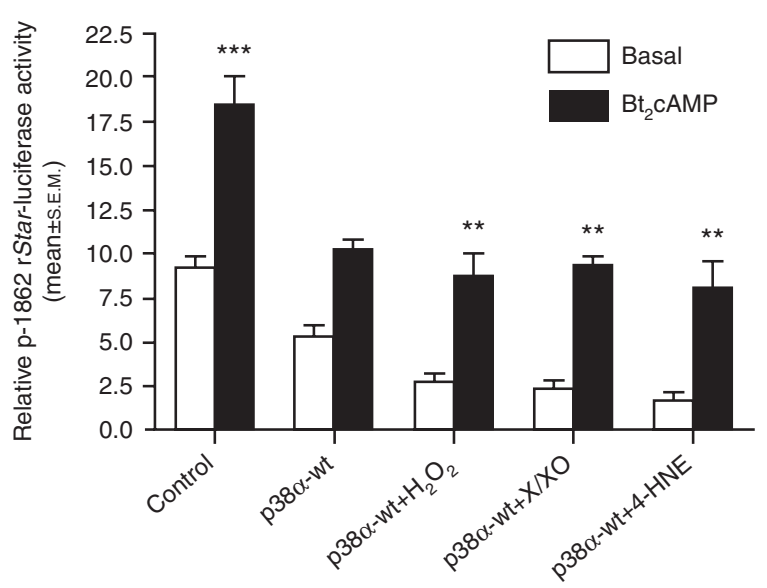

Figure 4

Evaluation of the effects of p38 MAPK $\alpha$ (wt) overexpression and the effects of $\mathrm{X} / \mathrm{XO}$ generated $\mathrm{O}_{2}^{-}, \mathrm{H}_{2} \mathrm{O}_{2}$, and 4-HNE on basal and cAMP-stimulated rat Star promoter (luciferase) activity in MLTC-1 cells. MLTC-1 cells were transiently transfected with a rat p-1862 Star-Luc (firefly luciferase) construct $(1 \mu \mathrm{g})+$ Renilla luciferase (R/uc, pRL-TK) $(50 \mathrm{ng})$ and \pm native p38 MAPK $\alpha(w \mathrm{t})(1 \mu \mathrm{g})$ using Lipofectamine 2000 . After $48 \mathrm{~h}$, dishes were exposed to \pm xanthine $(0.1 \mathrm{mM}) / \mathrm{XO}(10 \mathrm{mU} / \mathrm{ml}), \pm 50 \mu \mathrm{M} \mathrm{H}_{2} \mathrm{O}_{2}$, or $\pm 50 \mu \mathrm{M}$ 4-hydroxynonenol (4-HNE) for $1 \mathrm{~h}$, washed, incubated with or without $\mathrm{Bt}_{2} \mathrm{CAMP}(2.5 \mathrm{mM})$ for $5 \mathrm{~h}$, cells were lysed using cell lysis buffer (Promega Corporation) and subsequently assayed for both firefly and Renilla luciferase activities using a Promega Dual-Luciferase Reporter Kit (E1980). In some cases, cell lysates were subjected to SDS-PAGE followed by western blotting analysis and the quantification of the total and the phosphorylated p38 MAPK $\alpha$ bands. (A) Western blots showing the bands stained for either total p38 MAPK $\alpha$ or its phosphorylated form. (B) Rat Star promoter luciferase activity. ${ }^{* *} P<0.01$ basal (control) vs $\mathrm{Bt}_{2}$ CAMP and $* * * P<0.0001$ basal (control) vs $\mathrm{Bt}_{2}$ CAMP. 
$\mathrm{Tyr}^{182}$ (approximately 10-30\% (phopsho-p38 MAPK:total p38 MAPK ratios: control $=1.00$; superoxide anion $=1.08$; $\mathrm{H}_{2} \mathrm{O}_{2}=1.34$; and $\left.\mathrm{HNE}=1.24\right)$ ). Basal levels of Star promoter luciferase activity were significantly decreased when cells were co-transfected with a p38 MAPK $\alpha$ construct (Fig. 4B). Basal promoter activity was further decreased when p38 MAPK $\alpha$-transfected cells were exposed to oxidants: superoxide anion $\left(\mathrm{O}_{2}^{-}\right), \mathrm{H}_{2} \mathrm{O}_{2}$, or 4-HNE (Fig. 4B). Likewise, cAMP-stimulated promoter activity was also decreased with the introduction of p38 MAPK $\alpha$. However, no additional decreases in cAMP-stimulated promoter activity were noted following oxidant exposure of p38 MAPK $\alpha$ transfected cells (Fig. 4B). These p38 MAPK $\alpha$ overexpression studies indicate that inhibitory actions of oxidants on Star promoter activity are mediated by p38 MAPK $\alpha$.

\section{Effects of overexpression of native (wt) and dn p38 MAPK isoforms on Star promoter activity}

The above findings indicate that p38 MAPK $\alpha$ exerts a negative effect on both basal and cAMP-stimulated Star promoter activity. To establish p38 MAPK isoform specificity, we next examined the relative efficacy of native (wt) p38 MAPK $\alpha$, p38 MAPK $\beta$, p38 MAPK $\gamma$, and p38 MAPK $\delta$ and their respective $d n$ forms on Star promoter activity. MLTC-1 cells were transfected with STAR-reporter luciferase plasmid alone or together with plasmids encoding native or dn FLAG-p38 MAPK isoforms, and luciferase activities were quantified. As before, expression of wt p38 MAPK $\alpha$-wt reduced the basal promoter activity by approximately 50\%, whereas expression of dn p38 MAPK $\alpha$-dn enhanced the basal promoter activity by about twofold (Fig. 5A). Qualitatively similar results were obtained when Y-1 or HEK-293 cells were substituted for MLTC-1 or rat Star promoter (p-1862-rat StAR) reporter construct was replaced with a mouse Star promoter reporter construct (p960-mouse Star; Manna et al. (2002); data not shown). Results presented in Fig. 5B and $\mathrm{C}$ show that overexpression of p38 MAPK $\beta$-wt or p38 MAPK $\gamma$-wt also significantly suppressed the transfected rat Star promoter reporter activity both under basal conditions and in response to cAMP stimulation. On the other hand, expression of p38 MAPK $\beta$-dn, similar to p38 MAPK $\alpha$-dn, enhanced basal as well as cAMP-stimulated promoter activity, but the use of p38 MAPK $\gamma$-dn showed no such stimulatory effect. In contrast, expression of p38 MAPK $\delta$ wt showed no inhibitory effect on promoter activity when measured under basal conditions, but significantly decreased cAMP-stimulated promoter activity (Fig. 5D). On the other hand, transient overexpression of p38 MAPK $\delta$-dn variably but significantly enhanced cAMPstimulated promoter activity (Fig. 5D). These results led us to conclude that p38 MAPK $\alpha$ and to a lesser extent p38 MAPK $\beta$, p38 MAPK $\gamma$, and p38 MAPK $\delta$ function as negative regulators of Star gene transcription.

To further establish the inhibitory action of p38 MAPK $\alpha$ on Star promoter activity, p38 MAPK inhibitor experiments were carried out. To this end, MLTC-1 cells were either transfected with Star promoter alone or Star promoter plus p38 MAPK $\alpha$-wt construct and then treated with selective inhibitors of p38 MAPK, SB203580 and SB202190 (Bain et al. 2007). Luciferase measurement results indicated that SB203580 or SB202190 treatment resulted in a small increase in basal promoter activity in MLTC-1 cells transfected with Star promoter alone (Table 2). Co-transfection of Star promoter with p38
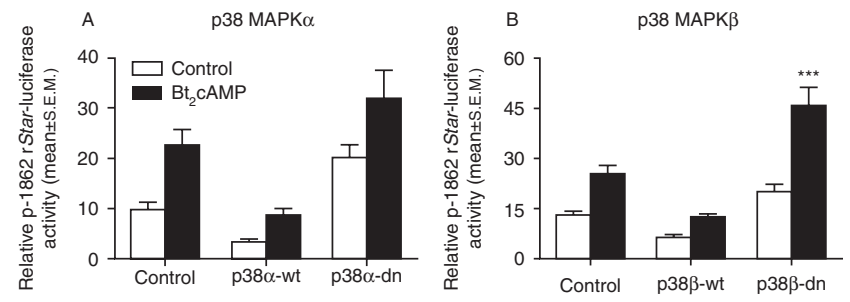

Figure 5

Effects of overexpression of wt and dn p38 MAPK $\alpha$, p38 MAPK $\beta$, p38 MAPK $\gamma$, and p38 MAPK $\delta$ constructs on Star promoter activity in MLTC-1 cells. The cells were transiently transfected with p-1862 Star-Luc (firefly luciferase) construct plus Renilla luciferase (R/uc, pRL-TK), and empty vector, p38 MAPK $\alpha$-wt, p38 MAPK $\alpha$-dn, p38 MAPK $\beta$-wt, p38 MAPK $\beta$-dn, p38 MAPK $\gamma$-wt, p38 MAPK $\gamma$-dn, p38 MAPK $\delta$-wt, or p38 MAPK $\delta$-dn. Fortyeight hours after transfection, the dishes were washed and subsequently incubated with or without $\mathrm{Bt}_{2} \mathrm{CAMP}(2.5 \mathrm{mM})$ for $5 \mathrm{~h}$ and cells lysed using
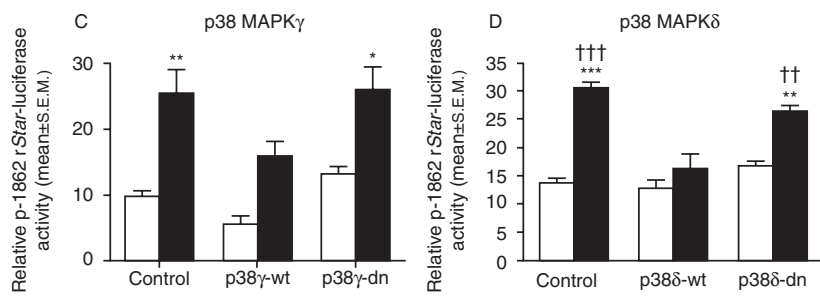

cell lysis buffer (Promega Corporation) and subsequently assayed for both firefly and Renilla luciferase activities. (A) p38 MAPK $\alpha$, (B) p38 MAPK $\beta$, (C) p38 MAPK $\gamma$, and (D) p38 MAPK $\delta$. Each value represents mean \pm s.E.M. of four separate determinations. wt (native); dn, dominant negative. ${ }^{*} P<0.01$ basal (control) vs $\mathrm{Bt}_{2} \mathrm{CAMP} ; * * P<0.01$ basal (control) vs $\mathrm{Bt}_{2} \mathrm{CAMP}$;

$* * * P<0.0001$ basal (control) vs $\mathrm{Bt}_{2} \mathrm{CAMP} ;{ }^{{ }^{\dagger}} P<0.01 \mathrm{Bt}_{2} \mathrm{CAMP}$ p38 $\delta$-dn vs $\mathrm{Bt}_{2}$ CAMP p38 $\alpha$-wt; and ${ }^{+++} P<0.0001 \mathrm{Bt}_{2}$ CAMP control vs $\mathrm{Bt}_{2} \mathrm{CAMP}$ p38 $\alpha$-wt.

Published by Bioscientifica Ltd. 
Table 2 Effects of p38 MAPK inhibitors and overexpression of native/wt and dominant negative (dn) forms of p38 MAPK $\alpha$ either separately or in combination on Star promoter (luciferase) activity in MLTC-1 cells. Mouse Leydig tumor cells MLTC1 were transiently transfected with rat p-1862 rStAR-luc (firefly luciferase) construct $(1 \mu \mathrm{g}) \pm$ plasmid-encoding native (wt) FLAG p38 MAPK $\alpha(1 \mu \mathrm{g})$. A control reporter construct containing Renilla luciferase (R/uc, pRL-TK; $50 \mathrm{ng}$ ) was co-transfected for normalization of transfection efficiency. After $48 \mathrm{~h}$, cells were incubated with or without $\mathrm{Bt}_{2} \mathrm{CAMP}(2.5 \mathrm{mM})$ for $4 \mathrm{~h}$ and then with or without SB203580 $(10 \mu \mathrm{M})$ or SB202190 $(10 \mu \mathrm{M})$ for an additional hour, harvested and analyzed for firefly and Renilla luciferase activities. Firefly luciferase activities were normalized to Renilla luciferase reporter activities and shown as -fold induction compared with control (empty vector). Each value represents mean \pm s.E.M. of four separate determinations

\begin{tabular}{lcc}
\hline Additions & & $\begin{array}{c}\text { Relative p-1862 rStAR-luc } \\
\text { activity (U) } \pm \text { s.E.M. }\end{array}$ \\
\hline SB203580 & $6.56 \pm 0.873^{*}$ \\
SB202190 & $7.76 \pm 0.850^{*}$ \\
p38 MAPK $\alpha$ & $2.96 \pm 0.807$ \\
SB203580+p38 MAPK $\alpha$ & $7.18 \pm 0.917^{\dagger}$ \\
SB202190+p38 MAPK $\alpha$ & $9.42 \pm 1.953^{\dagger}$ \\
\hline
\end{tabular}

${ }^{*} P<0.01$ p38 MAPK $\alpha$ vs SB203580 or SB202190 and ${ }^{\dagger} P<0.01$ p38 MAPK $\alpha$ vs $\mathrm{SB} 203580+$ p38 MAPK $\alpha$ or SB202190+p38 MAPK $\alpha$.

MAPK $\alpha$ resulted in an efficient reduction in Star promoter activity under basal conditions. This reduction in basal promoter activity was completely restored following treatment of transfected cells with either SB203580 or SB202190 (Table 2). Qualitatively similar results were obtained when luciferase measurements were carried out using extracts from cAMP-treated cells (data not shown).

The results presented in Fig. 6 demonstrate that transient overexpression of p38 MAPK $\alpha$-wt in MLTC- 1 cells significantly decreased the endogenous mRNA levels of STAR protein both under basal conditions and in response to cAMP stimulation. In contrast, transient overexpression of a p38 MAPK $\alpha$-dn significantly upregulated both basal as well as cAMP-stimulated Star mRNA levels. These results further confirmed that p38 MAPK $\alpha$ negatively regulates the gene transcription of STAR protein.

\section{MKK3 and MKK6 contribute to the p38 MAPK-mediated suppression of Star promoter activity}

Two closely related dual-specificity upstream protein kinases, MKK3 and MKK6, phosphorylate and activate p38 MAPK at the activation site Thr-Gly-Tyr (Han et al. 1996, Enslen et al. 1998, Wysk et al. 1999, Coulthard et al.
2009, Cuadrado \& Nebreda 2010, Remy et al. 2010). We determined whether MKK3 and MKK6 play a role in p38 MAPK-mediated suppression of Star promoter activity. MLTC-1 cells (which express predominantly p38 MAPK $\alpha$ but also significant amount of p38 MAPK $\beta$, Fig. 2) were co-transfected with a rat Star firefly luciferase reporter construct as described earlier (rat p-1862 StAR-Luc) plus a reporter construct containing Renilla luciferase (Rluc, pRL-TK) with or without a plasmid encoding a ca form of MKK3/MMK6, FLAG-MKK3-ca (MKK3 (EE))/FLAG-MKK6ca (MKK6 (EE)), or a dn MKK3/MKK6, FLAG-MKK3-dn (MKK (AA))/FLAG-MKK6-dn (MKK (AA)). After $48 \mathrm{~h}$, the cells were treated with or without $\mathrm{Bt}_{2} \mathrm{CAMP}(2.5 \mathrm{mM})$ for $5 \mathrm{~h}$, harvested, and cell extracts analyzed for dual luciferase activities. As shown in Fig. 7A, overexpression of MKK3-ca significantly reduced both basal and cAMPstimulated promoter activity. In contrast, transfections with an MKK3-dn construct upregulated both the basal as well as cAMP-stimulated reporter activity. Likewise, overexpression of MKK6-ca led to a significant inhibition of basal and cAMP-stimulated Star promoter activity (Fig. 7A). Similar to the effect of the dn form of MKK3, overexpression of MKK6-dn also enhanced promoter activity both under basal conditions and in response to cAMP stimulation. These results imply that both MKK3 and MKK6 are equally effective and participate in p38 MAPK-mediated repression of Star promoter activity.

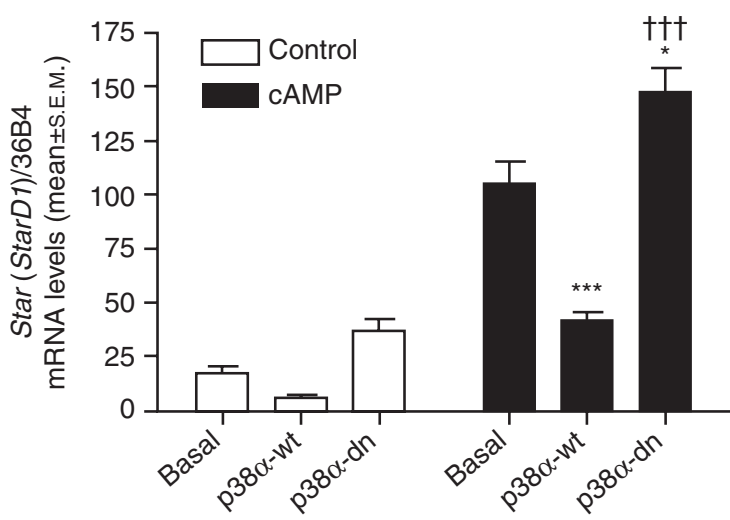

Figure 6

Effects of transient overexpression of wt and dominant-negative p38 MAPK $\alpha$ on basal and cAMP-stimulated endogenous mRNA levels of Star in MLTC-1 cells. MLTC-1 cells were transiently transfected with empty vector, p38 MAPK $\alpha$-wt, or p38 MAPK $\alpha$-dn and, $48 \mathrm{~h}$ after transfection, the dishes were washed and subsequently incubated with or without $\mathrm{Bt}_{2} \mathrm{CAMP}$ $(2.5 \mathrm{mM})$ for $5 \mathrm{~h}$. Following incubation, the dishes were subjected to total RNA isolation and the RNA samples quantified for Star (StarD1) mRNA levels by qRT-PCR. Each value represents mean \pm s.E.M. of four separate determinations. ${ }^{*} P<0.01 \mathrm{Bt}_{2} \mathrm{CAMP}$ p38 $\alpha$-dn vs basal (control) $\mathrm{Bt}_{2} \mathrm{CAMP}$; $\star * * P<0.01 \mathrm{Bt}_{2} \mathrm{CAMP}$ p38 $\alpha$-wt vs basal (control) $\mathrm{Bt}_{2} \mathrm{CAMP}$; and ${ }^{++t} P<0.001$ $\mathrm{Bt}_{2}$ CAMP p38 $\alpha$-dn vs $\mathrm{Bt}_{2}$ CAMP p38 $\alpha$-wt.

Published by Bioscientifica Lto. 

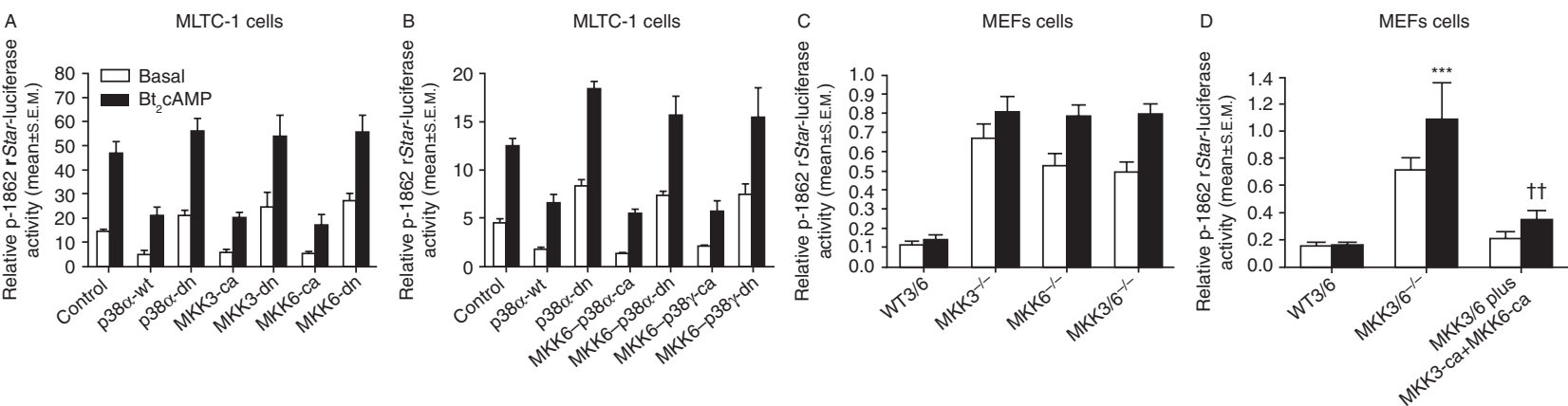

\section{Figure 7}

Regulation of Star promoter activity in MITC-1 cells in response to transient overexpression of MKK3, MKK6, or MKK6-p38 MAPK $\alpha / \gamma$ constructs and mouse embryonic fibroblasts (MEFs) lacking MKK3, MKK6, or both (A) MLTC-1 cells were cotransfected with p-1862 Star-Luc (firefly luciferase) construct $(1 \mu \mathrm{g})$ plus Renilla luciferase (R/uc, pRL-TK) (50 ng), and empty vector, p38 MAPK $\alpha-w t$, p38 MAPK $\alpha-d n$, MKK3-ca, MKK3-dn, MKK6-ca, or MKK6-dn. At the end of $48 \mathrm{~h}$, the dishes were treated with or without $\mathrm{Bt}_{2} \mathrm{CAMP}(2.5 \mathrm{mM})$ for an additional $5 \mathrm{~h}$ and subsequently cell lysates assayed for firefly and Renilla luciferase activities. (B) MLTC-1 cells were transiently transfected with empty vector, p38 MAPK $\alpha$-wt, p38 MAPK $\alpha$-dn, MKK6-p38 MAPK $\alpha$-ca, MKK6-p38 MAPK $\alpha$-dn, MKK6-p38 MAPK $\gamma$-ca, or MKK6-p38 MAPK $\gamma$-dn and, after $48 \mathrm{~h}$, further treated with or without $\mathrm{Bt}_{2} \mathrm{CAMP}$ for $5 \mathrm{~h}$. Cell lysates were assayed for firefly and Renilla luciferase activities as described above. (C) Wt (MKK3/6) MEFs and MEFs deficient in $\mathrm{MKK}^{-1-}$, MKK $6^{-1-}$, or both (MKK3 $3^{-1-} / \mathrm{MKK}^{-1-}$ ) were co-transfected with p-1862 Star-Luc (firefly luciferase) and Renilla luciferase (Rluc, pRL-TK) constructs for $48 \mathrm{~h}$, stimulated with or without $\mathrm{Bt}_{2} \mathrm{CAMP}$ for an additional $5 \mathrm{~h}$, followed by determination of firefly and Renilla luciferase activities.

Next we undertook the approach of enzyme-substrate fusion (Robinson et al. 1998, Zheng et al. 1999, Qi et al. 2007) to further examine the MKK-p38 MAPK regulation of Star promoter activity. This approach is based on the fact that p38 MAPK becomes ca when linked to its upstream activator such as MKK6 (Qi et al. 2007). Herein, we used constructs in which p38 MAPK $\alpha$-ca, p38 MAPK $\gamma$-ca, p38 $/$ AGF-dn, or p38 $\gamma /$ AGF-dn (representative p38 MAPKs) were fused in-frame with the activator MKK6 (MKK6 activates all isoforms of p38 MAPK) through a decapeptide linker as reported previously by Qi et al. (2007). MLTC-1 cells were transiently transfected with Star promoter with or without expression vector encoding HA-MKK6-p38 MAPK $\alpha$-ca, HA-MKK6-p38 MAPK $\gamma$-ca, HA-MKK6-p38 $\alpha /$ AGF-dn, or HA-MKK6-p38 $\gamma /$ AGF-dn, and after $48 \mathrm{~h}$ cell lysates were analyzed for firefly and Renilla luciferase activities. As a positive control, some dishes were also transfected with p38 MAPK $\alpha$ (wt) or p38 MAPK $\alpha$-dn plasmid DNA. Results presented in Fig. 7B demonstrate that transfection of cells with either MKK6-p38 MAPK $\alpha$-ca or MKK6-p38 MAPK $\gamma$-ca suppressed the expression of Star promoter activity, whereas use of MKK6-p38 MAPKa/AGFdn or MKK6-p38 MAPK $\gamma / A G F-d n$ enhanced the promoter
(D) MKK3/6 and $M K K 3^{-1-} / \mathrm{MKK}^{-1-}$ DKO MEFs were co-transfected with p-1862 Star-Luc (firefly luciferase) and Renilla luciferase (R/uc, pRL-TK) constructs. In a third set $\mathrm{MKK}^{-1-} / \mathrm{MKK}^{-1-}$ DKO MEFs were co-transfected with MKK3-ca + MKK6-ca plus p-1862 Star-Luc (firefly luciferase) and Renilla luciferase (R/uc, pRL-TK) constructs for $48 \mathrm{~h}$ followed by treatment with $\pm \mathrm{Bt}_{2} \mathrm{CAMP}$. Cell lysates were assayed for firefly and Renilla luciferase activities, as described earlier. Each value represents mean \pm s.E.M. of four separate determinations. ca, constitutively active; dn, dominant negative. All values presented (A) show statistically significant differences between basal vs $\mathrm{Bt}_{2} \mathrm{CAMP}$ and basal (control) or basal Bt ${ }_{2} \mathrm{CAMP}$ vs $\mathrm{p} 38 \alpha$-wt, MKK3-ca, or MKK6-ca. The values presented in (B) show statistically significant differences between basal vs $\mathrm{Bt}_{2} \mathrm{CAMP}$ and basal (control) or basal $\mathrm{Bt}_{2} \mathrm{CAMP}$ vs p38 $\alpha$-wt, MKK6-p38 $\alpha$-ca, or MKK6-p38 $\gamma$-ca. (C) Basal (control) or basal $\mathrm{Bt}_{2} \mathrm{CAMP}$ WT3/6 show statistically significant differences from the corresponding $\mathrm{Bt}_{2} \mathrm{CAMP}_{\mathrm{MKK}}{ }^{-1-}$, $\mathrm{MKK}^{-1-}$, or $\mathrm{MKK} 3 / 6^{-1-}$ groups. (D) $* * * P<0.001$ wt MKK3/6 $\mathrm{Bt}_{2} \mathrm{CAMP}$ vs MKK3/6 ${ }^{-1-} \mathrm{Bt}_{2} \mathrm{CAMP}$; and ${ }^{+\dagger} P<0.01 \mathrm{MKK} 3 / 6{ }^{-1-} \mathrm{Bt}_{2}$ CAMP vs MKK3/6 plus MKK3-ca + MKK6-ca $\mathrm{Bt}_{2} \mathrm{CAMP}$.

activity. As expected, transfection of cells with p38 MAPK $\alpha$ wt or p38 MAPK $\alpha$-dn decreased and increased the promoter activity respectively. Thus, p38 MAPKs, including p38 MAPK $\alpha$ and their upstream activators MKK3 and MKK6, work in concert to modulate Star promoter activity.

To more directly define the roles that MKK3 and MKK6 play in p38 negative regulation of the Star promoter activity mediated by MAPKs, we assessed the expression of Star promoter activity in MEFs with targeted disruption of Mkk3 (Map2k3), Mkk6 (Map2k6) or both Mkk3 and Mkk6 genes. MKK3/6 (wt), $\mathrm{MKK}^{-1-}, \mathrm{MKK}^{-1-}$, and $\mathrm{MKK} 3 / 6^{-1-}$ (DKO) MEFs (Brancho et al. 2003) were transfected with a rat Star reporter construct $(48 \mathrm{~h})$, treated with or without $\mathrm{Bt}_{2} \mathrm{CAMP}(2.5 \mathrm{mM}, 5 \mathrm{~h})$, and, subsequently, cell lysates analyzed for luciferase activities. As shown in Fig. 7C, expression of Star promoter activity was substantially higher (both basal and cAMP stimulated) in single $\mathrm{MKK}^{-1-}$ or MKK6 ${ }^{-1-}$ MEFs as compared with wt MEFs that express both MKK3 and MKK6. Interestingly, use of MKK3 $/ 6^{-/-}$DKO MEFs produced no additive effect, indicating that MKK3 and MKK6 play complementary roles and activate similar p38 MAPKs, such as p38 MAPK $\alpha$ that mediate negative regulation of Star promoter activity.

Published by Bioscientifica Ltd. 
Finally, the results presented in Fig. 7D demonstrate that simultaneous overexpression of MKK3-ca and MKK6-ca in MKK3 $/ 6^{-1-}$ DKO MEFs significantly decreased both basal and c-AMP-stimulated Star promoter luciferase activity as compared with cells transfected with the control DNA.

\section{CAMP-stimulated Star mRNA and progesterone levels in relation to $\mathrm{p} 38 \mathrm{MAPK}$}

The above studies provided strong evidence that p38 MAPKs, particularly p38 MAPK $\alpha$, function as negative regulators of Star promoter activity. We next evaluated the inhibitory actions of p38 MAPK $\alpha$ on steady-state Star mRNA levels and its relevance to steroidogenesis. Expression of p38 MAPK $\alpha$-wt significantly decreased both basal and cAMP-induced Star mRNA levels. In contrast, when MLTC-1 cells were transfected with p38 MAPK $\alpha$-dn, basal and cAMP-stimulated levels were significantly increased compared with levels for the control cells and the cells transfected with p38 MAPK $\alpha$-wt (data not shown).

We also measured progesterone synthesis and secretion in the culture medium from cells transfected with either p38 MAPK $\alpha$-wt or p38 MAPK $\alpha-d n$ and subsequently stimulated without or with $\mathrm{Bt}_{2} \mathrm{CAMP}$. As shown in Table 3, progesterone accumulation in each case paralleled changes in Star mRNA expression. The nonstimulated MLTC-1 cells transiently expressing p38 MAPK $\alpha$ (wt) decreased progesterone production by approximately $75-80 \%$, whereas expression of p38

Table 3 Effects of overexpression of native/wt and dominantnegative $(\mathrm{dn})$ forms of p38 MAPK $\alpha$ on steroid secretion by MLTC-1 cells. Mouse Leydig tumor cells, MLTC, were transiently transfected with empty vector, plasmid-encoding native (wt) FLAG p38 MAPK $\alpha(1 \mu \mathrm{g})$, or dn Flag p38 MAPK $\alpha(1 \mu \mathrm{g})$. After $48 \mathrm{~h}$, cells were treated with or without $\mathrm{Bt}_{2} \mathrm{CAMP}(2.5 \mathrm{mM})$ for $5 \mathrm{~h}$ and subsequently culture medium samples collected and analyzed for progesterone secretion by RIA. Each value represents mean \pm s.E.M. of four separate determinations

\begin{tabular}{lc} 
Additions & $\begin{array}{c}\text { ng Progesterone } \\
\text { secreted } / \mathbf{1 0}\end{array}$ \\
cells/5 $\mathbf{h} \pm$ s.E.M. \\
\hline Basal & $8.53 \pm 0.45^{\star}$ \\
Bt ${ }_{2}$ CAMP $(2.5 \mathrm{mM})$ & $34.83 \pm 3.01^{\ddagger}$ \\
p38 MAPK $\alpha$-wt & $2.43 \pm 0.41$ \\
p38 MAPK $\alpha-w t+\mathrm{Bt}_{2} \mathrm{CAMP}(2.5 \mathrm{mM})$ & $17.20 \pm 0.33^{\dagger}$ \\
p38 MAPK $\alpha-d n$ & $17.84 \pm 0.95^{\dagger}$ \\
p38 MAPK $\alpha-d n+\mathrm{Bt}_{2} \mathrm{CAMP}(2.5 \mathrm{mM})$ & $72.33 \pm 1.84^{\S}$ \\
\hline
\end{tabular}

${ }^{*} P<0.05$ basal (control) vs p38 MAPK $\alpha$-wt; ${ }^{\dagger} P<0.001 \mathrm{Bt}_{2}$ CAMP vs MAPK $\alpha-$ wt; ${ }^{\ddagger} P<0.01$ MAPK $\alpha$-wt vs p38 MAPK $\alpha$-wt $+\mathrm{Bt}_{2}$ CAMP or p38 MAPK $\alpha$-dn; and ${ }^{\S} P<0.001$ MAPK $\alpha$-wt vs p38 MAPK $\alpha-d n+B t_{2}$ CAMP.
MAPK $\alpha$-dn increased medium progesterone levels by approximately twofold. Likewise, cAMP-stimulated progesterone secretion by $\mathrm{p} 38 \mathrm{MAPK} \alpha$-wt-expressing cells was reduced by approximately 50\% when compared with that seen in control cells. On the other hand, expression of p38 MAPK $\alpha$-dn resulted in approximately a twofold increase in cAMP-stimulated progesterone production as compared with control cells (Table 3).

\section{Effect of p38 MAPK on CREB-mediated regulation of Star promoter activity}

Expression of Star is mainly regulated at the transcriptional level through a cAMP-protein kinase A (PKA)dependent mechanism (Manna et al. 2009). Herein, we examined the effect of p38 MAPK on CREB-mediated regulation of Star promoter activity. As the CREBdependent transcriptional response is primarily dependent on CREB phosphorylation (Shaywitz \& Greenberg 1999, Johannessen et al. 2004, Altarejos \& Montminy 2011), we initially examined the effects of p38 MAPK $\alpha$-wt and p38 MAPK $\alpha$-dn on the cAMP/PKA-stimulated phosphorylation ( $\operatorname{Ser}^{133}$ ) of CREB protein in MLTC-1 cells. The results presented in Fig. 8 demonstrate the effects of p38 MAPK $\alpha$-wt and p38 MAPK $\alpha$-dn constructs on the levels of the $\mathrm{CAMP} / \mathrm{PKA}$-stimulated phosphorylated form of CREB (p-CREB). Transfection of cells with p38 MAPK $\alpha-w t$ increased cAMP-stimulated phospho-CREB levels, and the use of p38 MAPK $\alpha$-dn resulted in much greater stimulation of its phospho-levels.

The results presented in Fig. 8 also demonstrate that phosphorylation of ATF-1, which is 65\% identical to CREB in its primary amino acid sequence (Shaywitz \& Greenberg 1999), was also increased in response to the overexpression of p38 MAPK $\alpha$-wt or p38 MAPK $\alpha$-dn construct. The potential effect of p38 MAPK $\alpha$ on CREB was further studied in MLTC-1 cells using a CRE-reporter (luciferase) construct. The data presented in Fig. 9A show that transient transfection of MLTC-1 cells with CRE, CREB, and p38 MAPK $\alpha$-wt resulted in a significant reduction in basal CRE-luciferase activity as compared with cells transfected with CRE alone or CRE+CREB. In contrast, transient expression of CRE, CREB, and p38 MAPK $\alpha$-dn in these cells resulted in an approximately 50\% increase in basal CRE-luciferase activity compared with results obtained with CRE or CRE + CREB construct. Results presented in Fig. 9B demonstrate that co-transfection of the cells with p38 MAPK $\alpha$-wt decreased the $\mathrm{Bt}_{2} \mathrm{cAMP}$ induced luciferase activity. Expression of p38 MAPK $\alpha$-dn construct, however, showed no effect on CRE-luciferase

Published by Bioscientifica Ltd. 

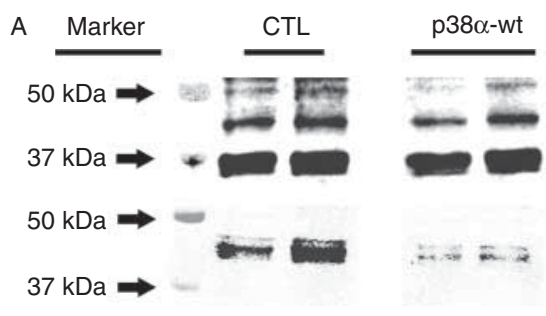

B

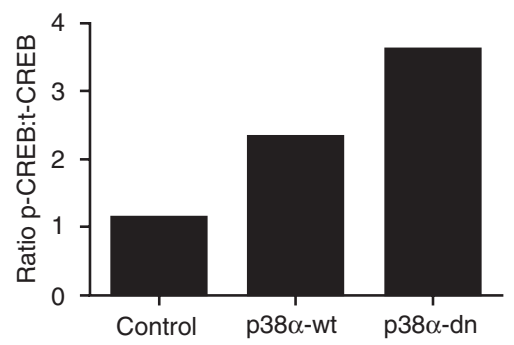

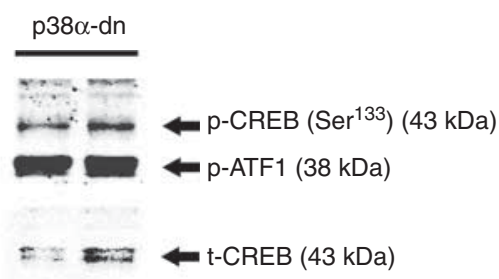

C

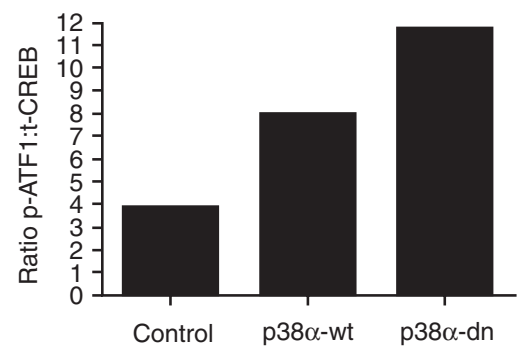

Figure 8

Effects of overexpression of p38 MAPK $\alpha$-wt and p38 MAPK $\alpha$-dn on the levels of total ( $t$ ) and phospho-forms of CREB in response to treatment of cells with or without $\mathrm{Bt}_{2} \mathrm{CAMP}$. Cells were transfected with either an empty vector, p38 MAPK $\alpha-w t$, or p38 MAPK $\alpha$-dn, and, after $48 \mathrm{~h}$, treated with or without $\mathrm{Bt}_{2} \mathrm{CAMP}$. The cell lysates were subjected to SDS-PAGE followed by

activity in response to cAMP stimulation (Fig. 9B). We also evaluated the effects of overexpression of p38 MAPK $\alpha$-wt and p38 MAPK $\alpha$-dn on AP1 (TRE) luciferase activity in MLTC-1 cells. As illustrated in Fig. 9C and D, transient expression of p38 MAPK $\alpha$-wt or p38 MAPK $\alpha$-dn, however, showed no effect on AP1 luciferase activity either under basal conditions or in response to TPA stimulation. These results led us to conclude that p38 MAPK $\alpha$ inhibits cAMPinduced Star promoter activity primarily by interfering
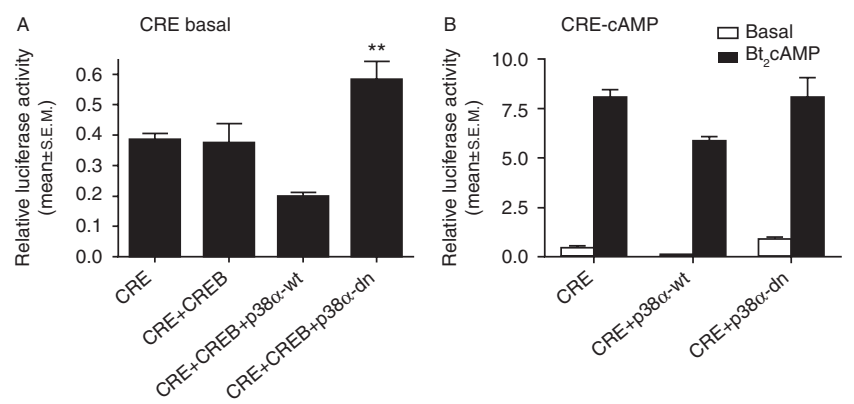

\section{Figure 9}

p38 MAPK $\alpha$-mediated downregulation of CRE (A and B), but not AP1/TRE (C and D), reporter activity in MLTC-1 cells. MLTC-1 cells were transfected with Cre-Luc (firefly luciferase) + Renilla luciferase (R/uc, pRL-TK), with or without CREB, or CREB + p38 MAPK $\alpha$-wt or p38 MAPK $\alpha$-dn for $48 \mathrm{~h}$. At the end of the incubation, washed dishes were further incubated with or without $\mathrm{Bt}_{2}$-CAMP followed by measurement of firefly and Renilla luciferase activities. Likewise, cells were transfected with AP1/TRE-luc (firefly western blotting analysis. The blots were developed using anti-CREB (total) or anti-phospho-CREB $\left(\mathrm{Ser}^{133}\right)$. (A) Western blot of $p$-CREB, t-CREB and p-ATF. (B) Quantification of ratios of p-CREB:t-CREB. (C) Quantification of ratios of $p$-ATF:t-ATF. t, total; $p$, phosphorylated.

with the PKA-mediated CREB phosphorylation and its functional expression.

\section{Discussion}

STAR protein plays a pivotal role in the tropic peptide hormone-regulated acute phase of steroidogenesis, mediating the rate-limiting translocation of cholesterol from the OMM to the IMM, where side-chain cleavage enzyme
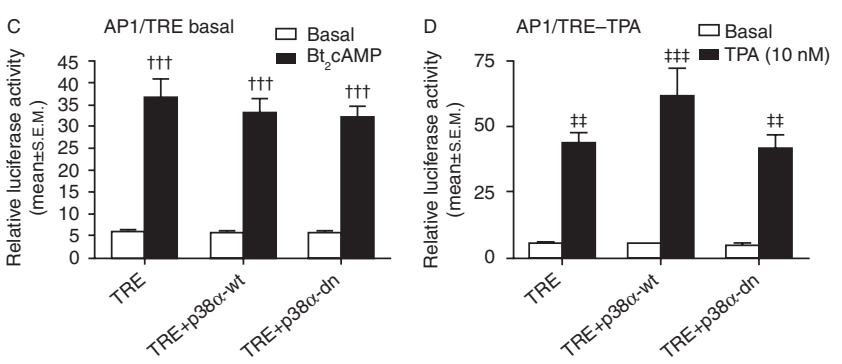

luciferase) + Renilla luciferase (R/uc, pRL-TK), with or without p38 MAPK $\alpha$ wt or p38 MAPK $\alpha$-dn, and, after $48 \mathrm{~h}$, dishes were further incubated with or without AP1/TRE activator TPA $(10 \mathrm{nM})$ for $30 \mathrm{~min}$. The cell lysates were then quantified for firefly and Renilla luciferase activities. Each value represents mean + S.E.M. of four separate determinations. $* * P<0.01$ CRE + CREB p38 $\alpha$ dn vs CRE + CREB p38 $\alpha$-wt; ${ }^{+t+} P<0.001$ basal (control) vs Bt ${ }_{2}$ CAMP; ${ }^{\ddagger \neq} P<0.01$ basal (control) vs TPA; and ${ }^{\ddagger \neq \ddagger} P<0.001$ basal (control) vs TPA.

Published by Bioscientifica Ltd. 
(P450scc; Cyp11A) carries out the first committed step in steroidogenesis, i.e. conversion of cholesterol to pregnenolone, the precursor of all steroid hormones (Stocco \& Clark 1996, Stocco 2001, Hu et al. 2010, Miller \& Bose 2011). We and others previously reported that expression of STAR protein is downregulated in both the adrenal gland and testicular Leydig cells of aging rats, and, as a result, adequate amounts of cholesterol are not transported to mitochondria, leading to defective steroidogenesis during aging (Leers-Sucheta et al. 1999, Luo et al. 2005, Wang et al. 2005, Sun et al. 2008). These changes have been linked to excessive oxidative stress and increased ROS production (Azhar et al. 1995, Chen et al. 2001, 2008, Cao et al. 2004, Abidi et al. 2008a,b, Zaidi et al. 2012). The observed increased expression of the active (phospho) form of oxidant-sensitive p38 MAPK $\alpha$ during aging led to the suggestion that this kinase mediates the anti-steroidogenic actions of excessive oxidative stress during aging (Abidi et al. 2008a,b). The current study examined the molecular mechanisms by which oxidant-sensitive p38 MAPK negatively affects Star gene transcription. Our initial qRT-PCR data indicate that Star (StarD1) is most abundantly expressed in both Y-1 and MLTC-1 cells and that $\mathrm{Bt}_{2} \mathrm{CAMP}$ stimulation further increased its mRNA levels by fourfold to fivefold in both cell types. The expression of StarD2 and StarD3, which belong to the same subgroup as StarD1 as well as a second subgroup of STARD proteins, STARD4, STARD5, and STARD6, was very low in Y-1 and MLTC-1 cells and their expression was not affected by cAMP stimulation of either cell type. These results are at variance with the results reported for another mouse Leydig tumor cell line, MA-10, where stimulation of cells with a cAMP analog was reported to stimulate mRNA expression of StarD4, in addition to a robust induction of StAR/StarD1 (Soccio et al. 2005). Similar to our data, however, the mRNA levels of StarD3 and StarD5 were induced by cAMP stimulation; the levels of StarD2, which is a phosphatidylcholine transfer protein (PCTP/StarD2) and StarD6, whose expression is limited to germ cells of testis (Soccio et al. 2002, Gomes et al. 2006, Bose et al. 2008), were not determined in this model Leydig cell line (Soccio et al. 2005). Interestingly, it has been shown that StarD6 exhibits similar activity to that of Star/StarD1 in inducing steroidogenesis in a cell-free mitochondrial system (Bose et al. 2008). Our qRT-PCR measurements also indicated that p38 MAPK $\alpha$ is the predominant endogenous isoform in both cell lines, although significant expression of p38 MAPK $\beta$ was also noted in MLTC-1 cells. In contrast, only low levels of p38 MAPK $\gamma$ and p38 MAPK $\delta$ were detected in both cell types. These results are in agreement with an earlier report from this laboratory (Abidi et al. 2008b), but are at variance with another report showing that p38 MAPK $\delta$ is expressed at very high levels in human steroidogenic tissues (Wang et al. 1997). Whether the low expression of $\mathrm{p} 38 \mathrm{MAPK} \delta$ noted here in mouse Y-1 adrenocortical tumor cells and mouse MLTC-1 Leydig tumor cells represents a species difference or tumor effect needs to be explored. As p38 MAPK $\alpha$ isoform (mRNA) is highly expressed in both Y-1 and MLTC- 1 cells, most of the studies aimed at defining the effects of p38 MAPK on Star/StarD1 gene transcription were carried out with p38 MAPK $\alpha$. However, we acknowledge that mRNA levels of the four p38 MAPKs in theory may not reflect the actual protein levels. Technical difficulties associated with currently available isoform-specific p38 MAPK antibodies, as well as lack of availability of p38 MAPK $\delta$ antibody, prevented us from measuring the protein levels of individual p38 MAPK isoforms.

In accordance with a previous observation that ROSmediated excessive oxidative stress inhibits steroidogenesis (Margolin et al. 1990, Gatzuli et al. 1991, Endo et al. 1993, Stocco et al. 1993, Kodaman et al. 1994, Musicki et al. 1994, Carlson et al. 1995, Diemer et al. 2003, Abidi et al. $2008 b$ ), our data demonstrate that treatment of Y-1 and MLTC-1 cells with oxidants, superoxide anion $\left(\mathrm{O}_{2}^{-}\right)$, $\mathrm{H}_{2} \mathrm{O}_{2}$, or a lipid peroxidation product, 4-HNE results in a significant reduction in the levels of Star mRNA both under basal conditions and in response to cAMP stimulation. In addition, we provide evidence that exposure of MLTC-1 cells transiently overexpressing p38 MAPK $\alpha$ to the above mentioned three oxidants resulted in increased phosphorylation (activation) of p38 MAPK $\alpha$, along with decreased Star promoter activity. The specificity studies demonstrated that p38 MAPK $\alpha$, p38 MAPK $\beta$, and p38 MAPK $\gamma$ were highly effective at suppressing Star promoter activity both under basal conditions and in response to cAMP stimulation, although p38 MAPK $\alpha$ was relatively more effective than p38 MAPK $\beta$ or p38 MAPK $\gamma$. In contrast, expression of dn forms of p38 MAPK $\alpha$, p38 MAPK $\beta$, or p38 MAPK $\gamma$ increased the expression of basal as well as cAMP-stimulated promoter activity. Likewise p38 MAPK $\alpha / \beta$ inhibitors, SB203580 or SB202190, prevented p38 MAPK $\alpha$-mediated suppression of promoter activity, further confirming that p38 MAPK functions as a negative regulator of Star gene transcription. Although overexpression of p38 MAPK $\delta$-wt construct exhibited no significant effect on basal Star promoter activity, transient overexpression of p38 MAPK $\delta$-dn, however, significantly increased the cAMP-stimulated promoter activity over the values seen with the use of p38 MAPK $\delta$-wt construct.

Published by Bioscientifica Ltd. 
Finally, use of various constructs of upstream activators of p38 MAPKs, MKK3 and MKK6 (Derijard et al. 1995, Raingeaud et al. 1995, 1996, Han et al. 1996), MKK6-p38MAPK $\alpha$, and MKK6-p38-MAPK $\gamma$ fusion constructs (Robinson et al. 1998, Zheng et al. 1999, Qi et al. 2007) and MEFs with targeted disruption of Mkk3, Mkk6, or both Mkk3 and Mkk6 genes (Brancho et al. 2003, Kang et al. 2006) further established that p38 MAPKs, particularly oxidant-sensitive p38 MAPK $\alpha$, are involved in the negative regulation of Star gene transcription.

Extensive evidence now indicates that the expression of Star is mainly regulated at the transcriptional level through a cAMP-PKA-dependent mechanism (Manna et al. 2009). Transcriptional activation of target genes by the cAMP-PKA signaling pathway is mainly achieved via cAMP-responsive element (CRE)-binding protein (CREB) transcription factor. cAMP-activated PKA catalyzes the phosphorylation of CREB at serine residue 133 (Altarejos \& Montminy 2011). Phosphorylation of CREB at $\operatorname{Ser}^{133}$ is required for CREB-induced gene transcription and promotes recruitment of the transcriptional co-activator CREB-binding protein (CBP) and its paralogue p300 (Mayr \& Montminy 2001). Although Star promoter lacks a consensus CRE (TGACGTCA), three CRE-like sites, CRE1, CRE2, and CRE3, have been characterized in the proximal region of the Star promoter (Manna et al. 2002), of which the CRE2 site overlaps with an AP1/TRE (5-TGA /CCTCA3)-binding site (Manna \& Stocco 2007) that can bind both CRE (CREB and its family member CRE modulator (CREM), and ATF1 and also ATF2) and AP1/TRE (Fos/Jun)binding proteins (Shaywitz \& Greenberg 1999, Shaulian \& Karin 2002). Our findings demonstrate that transient overexpression of p38 MAPK $\alpha$-wt increased phosphoCREB (p-Ser ${ }^{133}$ ) levels, and the use of p38 MAPK $\alpha$-dn resulted in a greater increase in phospho-CREB (p-Ser ${ }^{133}$ ) levels. Interestingly, neither p38 MAPK $\alpha$-wt nor p38 MAPK $\alpha$-dn increased the phosphorylation status of ATF1 , which is $65 \%$ identical to CREB in its primary amino acid sequence (Shaywitz \& Greenberg 1999). At present, we do not know the precise mechanism(s) by which p38 MAPK $\alpha$ and p38 MAPK $\alpha$-dn upregulate the cAMP-PKAmediated Ser ${ }^{133}$ phosphorylation of CREB. As CREB is also a substrate for the p38 MAPK-regulated MSK kinase (Hauge \& Frödin 2006), it is possible that both PKA and MSK simultaneously but variably catalyze CREB phosphorylation and in this process lead to increased CREB phosphorylation. The data obtained with the dn form of the p38 MAPK $\alpha$ raised another possibility that other kinases (e.g. PKC, calmodulin kinases, and glycogen synthase kinase; Impey \& Goodman 2001, Johannessen et al. 2004, Johannessen \& Moens 2007) that also phosphorylate CREB may cooperate with p38 MAP$\mathrm{K} \alpha / \mathrm{MSK}$ and interfere with the ability of PKA to catalyze Ser $^{133}$ phosphorylation. These various possibilities are likely to decrease CREB activity and, consequently, Star gene transcription and its promoter activity.

The potential effect of p38 MAPK $\alpha$ on CREB function was studied in MLTC-1 cells using a CRE-reporter (luciferase) approach. Various measurements led to the conclusion that p38 MAPK $\alpha$, by interfering with PKAmediated Ser ${ }^{133}$ phosphorylation of CREB, inhibits its function. On the other hand, both p38 MAPK $\alpha$-wt and p38 MAPK $\alpha$-dn proteins showed no significant effect on AP1 reporter activity. We used AP1 (TRE) as a control, because the CRE and AP1 (TRE) consensus sequences differ by only one nucleotide (CRE, TGACGTCA and AP1/TRE, TGACTCA) (Hai \& Curran 1991, Shaulian \& Karin 2002) and both recognition sequences can bind ATF/CREB and the Fos/Jun family of proteins, albeit with a variable affinity (Hai \& Curran 1991).

In summary, our data indicate that oxidant/ROS exposure of steroidogenic cells leads to simultaneous inhibition and activation of Star mRNA and phospho-p38 MAPK protein levels respectively. In addition, results regarding Star promoter activity reported in this study indicate that p38 MAPK $\alpha$ and to some extent p38 MAPK $\beta$ and p38 MAPK $\gamma$ inhibit Star gene transcription and that upstream kinases, MKK3 and MKK6, play a significant role in this process. Finally, our data provide evidence that p38 MAPK $\alpha$ negatively regulates Star gene transcription by potentially interfering with cAMP-PKA-mediated phosphorylation and the functional expression of the CREB transcription factor.

\section{Declaration of interest}

The authors declare that there is no conflict of interest that could be perceived as prejudicing the impartiality of the research reported.

\section{Funding}

This research was supported in part by the Department of Veterans Affairs (Office of Research and Development, Medical Research Service) and by grant numbers 2R01HL33881 and 1R01HL92473 from the National Institutes of Health.

\section{Author contribution statement}

$S K Z, W-J S, F B K$, and $S A$ conceived and designed the experiments; $S K Z$ performed the experiments; W-J S, F B K, and S A interpreted the results; S K Z, S B, W-J S, F B K, and S A drafted and edited the manuscript; $S B$ and $A B$ prepared the figures; $M P M, J H$, and $R J D$ provided critical reagents; and S K Z, W-J S, S B, A B, M P M, J H, R J D, F B K, and S A approved the final version of the manuscript.

Published by Bioscientifica Ltd. 


\section{References}

Abidi P, Leers-Sucheta S, Cortez Y, Han J \& Azhar S 2008a Evidence that agerelated changes in p38 MAP kinase contribute to the decreased steroid production by the adrenocortical cells from old rats. Aging Cell $\mathbf{7}$ 168-178. (doi:10.1111/j.1474-9726.2007.00364.x)

Abidi P, Zhang H, Zaidi SM, Shen W-J, Leers-Sucheta S, Cortez Y, Han J \& Azhar S 2008b Oxidative stress-induced inhibition of adrenal steroidogenesis requires participation of p38 mitogen-activated protein kinase signaling pathway. Journal of Endocrinology 198 193-207. (doi:10.1677/JOE-07-0570)

Altarejos JY \& Montminy M 2011 CREB and the CRTC co-activators: sensors for hormonal and metabolic signals. Nature Reviews. Molecular Cell Biology 12 141-151. (doi:10.1038/nrm3072)

Azhar S, Cao L \& Reaven E 1995 Alteration of the adrenal antioxidant defense system during aging in rats. Journal of Clinical Investigation 96 1414. (doi:10.1172/JCI118177)

Bain J, Plater L, Elliott M, Shpiro N, Hastie C, Mclauchlan H, Klevernic I, Arthur J, Alessi D \& Cohen P 2007 The selectivity of protein kinase inhibitors: a further update. Biochemical Journal 408 297-315. (doi:10.1042/BJ20070797)

Bose H, Whittal R, Ran Y, Bose M, Baker B \& Miller W 2008 StAR-like activity and molten globule behavior of StARD6, a male germ-line protein. Biochemistry 47 2277-2288. (doi:10.1021/bi701966a)

Brancho D, Tanaka N, Jaeschke A, Ventura J-J, Kelkar N, Tanaka Y, Kyuuma M, Takeshita T, Flavell RA \& Davis RJ 2003 Mechanism of p38 MAP kinase activation in vivo. Genes and Development 17 1969-1978. (doi:10.1101/ gad.1107303)

Cao L, Leers-Sucheta S \& Azhar S 2004 Aging alters the functional expression of enzymatic and non-enzymatic anti-oxidant defense systems in testicular rat Leydig cells. Journal of Steroid Biochemistry and Molecular Biology 88 61-67. (doi:10.1016/j.jsbmb.2003.10.007)

Carlson JC, Sawada M, Boone DL \& Stauffer JM 1995 Stimulation of progesterone secretion in dispersed cells of rat corpora lutea by antioxidants. Steroids 60 272-276. (doi:10.1016/0039-128X(94)00053-F)

Chen H, Cangello D, Benson S, Folmer J, Zhu H, Trush MA \& Zirkin BR 2001 Age-related increase in mitochondrial superoxide generation in the testosterone-producing cells of Brown Norway rat testes: relationship to reduced steroidogenic function? Experimental Gerontology 36 1361-1373. (doi:10.1016/S0531-5565(01)00118-8)

Chen H, Pechenino AS, Liu J, Beattie MC, Brown TR \& Zirkin BR 2008 Effect of glutathione depletion on Leydig cell steroidogenesis in young and old brown Norway rats. Endocrinology 149 2612-2619. (doi:10.1210/ en.2007-1245)

Corrêa SA \& Eales KL 2012 The Role of p38 MAPK and its substrates in neuronal plasticity and neurodegenerative disease. Journal of Signal Transduction 2012 649079. (doi:10.1155/2012/649079)

Coulthard LR, White DE, Jones DL, McDermott MF \& Burchill SA 2009 p38 MAPK: stress responses from molecular mechanisms to therapeutics. Trends in Molecular Medicine 15 369-379. (doi:10.1016/j.molmed.2009. 06.005)

Cuadrado A \& Nebreda A 2010 Mechanisms and functions of p38 MAPK signalling. Biochemical Journal 429 403-417. (doi:10.1042/BJ20100323)

Culty M, Luo L, Yao Z-X, Chen H, Papadopoulos V \& Zirkin BR 2002 Cholesterol transport, peripheral benzodiazepine receptor, and steroidogenesis in aging Leydig cells. Journal of Andrology 23 439-447. (doi:10.1002/j.1939-4640.2002.tb02251.x)

Derijard B, Raingeaud J, Barrett T, Wu I-H, Han J, Ulevitch RJ \& Davis RJ 1995 Independent human MAP-kinase signal transduction pathways defined by MEK and MKK isoforms. Science 267 682-685. (doi:10.1126/ science.7839144)

Diemer T, Allen JA, Hales KH \& Hales DB 2003 Reactive oxygen disrupts mitochondria in MA-10 tumor Leydig cells and inhibits steroidogenic acute regulatory (StAR) protein and steroidogenesis. Endocrinology 144 2882-2891. (doi:10.1210/en.2002-0090)
Endo T, Aten R, Leykin L \& Behrman H 1993 Hydrogen peroxide evokes antisteroidogenic and antigonadotropic actions in human granulosa luteal cells. Journal of Clinical Endocrinology and Metabolism 76 337-342. (doi:10.1210/jcem.76.2.7679398)

Enslen H, Raingeaud J \& Davis RJ 1998 Selective activation of p38 mitogenactivated protein (MAP) kinase isoforms by the MAP kinase kinases MKK3 and MKK6. Journal of Biological Chemistry 273 1741-1748. (doi:10.1074/jbc.273.3.1741)

Gatzuli E, Aten RF \& Behrman HR 1991 Inhibition of gonadotropin action and progesterone synthesis by xanthine oxidase in rat luteal cells. Endocrinology 128 2253-2258. (doi:10.1210/endo-128-5-2253)

Gomes C, Oh S-D, Kim J-W, Chun S-Y, Lee K, Kwon H-B \& Soh J 2006 Expression of the putative sterol binding protein Stard6 gene is male germ cell specific. Biology of Reproduction 72 651-658. (doi:10.1095/ biolreprod.104.032672)

Hai T \& Curran T 1991 Cross-family dimerization of transcription factors Fos/Jun and ATF/CREB alters DNA binding specificity. PNAS $\mathbf{8 8}$ 3720-3724. (doi:10.1073/pnas.88.9.3720)

Han J, Lee J, Bibbs L \& Ulevitch R 1994 A MAP kinase targeted by endotoxin and hyperosmolarity in mammalian cells. Science 265 808-811. (doi:10.1126/science.7914033)

Han J, Lee J-D, Jiang Y, Li Z, Feng L \& Ulevitch RJ 1996 Characterization of the structure and function of a novel MAP kinase kinase (MKK6). Journal of Biological Chemistry 271 2886-2891. (doi:10.1074/ jbc.271.6.2886)

Hauge C \& Frödin M 2006 RSK and MSK in MAP kinase signalling. Journal of Cell Science 119 3021-3023. (doi:10.1242/jcs.02950)

Hu J, Zhang Z, Shen W-J \& Azhar S 2010 Review: Cellular cholesterol delivery, intracellular processing and utilization for biosynthesis of steroid hormones. Nutrition \& Metabolism 7 47-72. (doi:10.1186/ 1743-7075-7-47)

Impey S \& Goodman R 2001 CREB signaling - timing is everything. Science's STKE 2001 pe1. (doi:10.1126/stke.2001.82.pe1)

Johannessen M \& Moens U 2007 Multisite phosphorylation of the cAMP response element-binding protein (CREB) by a diversity of protein kinases. Frontiers in Bioscience 12 1814-1832. (doi:10.2741/2190)

Johannessen M, Delghandi MP \& Moens U 2004 What turns CREB on? Cellular Signalling 16 1211-1227. (doi:10.1016/j.cellsig.2004.05.001)

Kang YJ, Seit-Nebi A, Davis RJ \& Han J 2006 Multiple activation mechanisms of p38 $\alpha$ mitogen-activated protein kinase. Journal of Biological Chemistry 281 26225-26234. (doi:10.1074/jbc.M606800200)

Kodaman P, Aten R \& Behrman H 1994 Lipid hydroperoxides evoke antigonadotropic and antisteroidogenic activity in rat luteal cells. Endocrinology 135 2723-2730. (doi:10.1210/endo.135.6.7988463)

Lee JC, Laydon JT, McDonnell PC, Gallagher TF, Kumar S, Green D, McNulty D, Blumenthal MJ \& Keys JR 1994 A protein kinase involved in the regulation of inflammatory cytokine biosynthesis. Nature $\mathbf{3 7 2}$ 739-46. (doi:10.1038/372739a0)

Leers-Sucheta S, Stocco DM \& Azhar S 1999 Down-regulation of steroidogenic acute regulatory (StAR) protein in rat Leydig cells: implications for regulation of testosterone production during aging. Mechanisms of Ageing and Development 107 197-203. (doi:10.1016/ S0047-6374(98)00149-3)

Liao C, Reaven E \& Azhar S 1993 Age-related decline in the steroidogenic capacity of isolated rat Leydig cells: a defect in cholesterol mobilization and processing. Journal of Steroid Biochemistry and Molecular Biology 46 39-47. (doi:10.1016/0960-0760(93)90207-D)

Liu J, Rone MB \& Papadopoulos V 2006 Protein-protein interactions mediate mitochondrial cholesterol transport and steroid biosynthesis. Journal of Biological Chemistry 281 38879-38893. (doi:10.1074/jbc. M608820200)

Luo L, Chen H \& Zirkin B 2001 Leydig cell aging: steroidogenic acute regulatory protein (StAR) and cholesterol side-chain cleavage enzyme. Journal of Andrology 22 149-156. (doi:10.1002/j.1939-4640.2001.tb02165.x)

Luo L, Chen H \& Zirkin BR 2005 Temporal relationships among testosterone production, steroidogenic acute regulatory protein (StAR), 
and P450 side chain cleavage enzyme (P450scc) during Leydig cell aging. Journal of Andrology 26 25-31. (doi:10.1002/j.1939-4640.2005. tb02868.x)

Manna PR \& Stocco DM 2007 Crosstalk of CREB and Fos/Jun on a single cis-element: transcriptional repression of the steroidogenic acute regulatory protein gene. Journal of Molecular Endocrinology 39 261-277. (doi:10.1677/JME-07-0065)

Manna PR, Dyson MT, Eubank DW, Clark BJ, Lalli E, Sassone-Corsi P, Zeleznik AJ \& Stocco DM 2002 Regulation of steroidogenesis and the steroidogenic acute regulatory protein by a member of the cAMP response-element binding protein family. Molecular Endocrinology 16 184-199. (doi:10.1210/mend.16.1.0759)

Manna PR, Dyson MT \& Stocco DM 2009 Role of basic leucine zipper proteins in transcriptional regulation of the steroidogenic acute regulatory protein gene. Molecular and Cellular Endocrinology 302 1-11. (doi:10.1016/j.mce.2008.12.009)

Margolin Y, Aten RF \& Behrman HR 1990 Antigonadotropic and antisteroidogenic actions of peroxide in rat granulosa cells. Endocrinology 127 245-250. (doi:10.1210/endo-127-1-245)

Mayr B \& Montminy M 2001 Transcriptional regulation by the phosphorylation-dependent factor CREB. Nature Reviews. Molecular Cell Biology 2 599-609. (doi:10.1038/35085068)

Miller WL \& Bose HS 2011 Early steps in steroidogenesis: intracellular cholesterol trafficking Thematic Review series: genetics of human lipid diseases. Journal of Lipid Research 52 2111-2135. (doi:10.1194/jlr.R016675)

Musicki B, Aten R \& Behrman H 1994 Inhibition of protein synthesis and hormone-sensitive steroidogenesis in response to hydrogen peroxide in rat luteal cells. Endocrinology 134 588-595. (doi:10.1210/endo.134.2. 7507829)

Popplewell P \& Azhar S 1987 Effects of aging on cholesterol content and cholesterol metabolizing enzymes in the rat adrenal gland. Endocrinology 121 64-73. (doi:10.1210/endo-121-1-64)

Pramanik R, Qi X, Borowicz S, Choubey D, Schultz RM, Han J \& Chen G 2003 p38 Isoforms have opposite effects on AP-1-dependent transcription through regulation of c-Jun the determinant role of the isoforms in the p38 MAPK signal specificity. Journal of Biological Chemistry 278 4831-4839. (doi:10.1074/jbc.M207732200)

Qi X, Pohl NM, Loesch M, Hou S, Li R, Qin J-Z, Cuenda A \& Chen G 2007 p38 $\alpha$ antagonizes p38 $\gamma$ activity through c-Jun-dependent ubiquitinproteasome pathways in regulating Ras transformation and stress response. Journal of Biological Chemistry 282 31398-31408. (doi:10.1074/jbc.M703857200)

Raingeaud J, Gupta S, Rogers JS, Dickens M, Han J, Ulevitch RJ \& Davis RJ 1995 Pro-inflammatory cytokines and environmental stress cause p38 mitogen-activated protein kinase activation by dual phosphorylation on tyrosine and threonine. Journal of Biological Chemistry $\mathbf{2 7 0}$ 7420-7426. (doi:10.1074/jbc.270.13.7420)

Raingeaud J, Whitmarsh AJ, Barrett T, Derijard B \& Davis RJ 1996 MKK3and MKK6-regulated gene expression is mediated by the p38 mitogenactivated protein kinase signal transduction pathway. Molecular and Cellular Biology 16 1247-1255.

Reaven E, Tsai L \& Azhar S 1995 Cholesterol uptake by the 'selective' pathway of ovarian granulosa cells: early intracellular events. Journal of Lipid Research 36 1602-1617.

Remy G, Risco AM, Iñesta-Vaquera FA, González-Terán B, Sabio G, Davis RJ \& Cuenda A 2010 Differential activation of p38MAPK isoforms by MKK6 and MKK3. Cellular Signalling 22 660-667. (doi:10.1016/j.cellsig. 2009.11.020)

Robinson MJ, Stippec SA, Goldsmith E, White MA \& Cobb MH 1998 A constitutively active and nuclear form of the MAP kinase ERK2 is sufficient for neurite outgrowth and cell transformation. Current Biology 8 1141-1152. (doi:10.1016/S0960-9822(07)00485-X)
Rouse J, Cohen P, Trigon S, Morange M, Alonso-Llamazares A, Zamanillo D, Hunt T \& Nebreda AR 1994 A novel kinase cascade triggered by stress and heat shock that stimulates MAPKAP kinase-2 and phosphorylation of the small heat shock proteins. Cell 78 1027-1037. (doi:10.1016/ 0092-8674(94)90277-1)

Roux PP \& Blenis J 2004 ERK and p38 MAPK-activated protein kinases: a family of protein kinases with diverse biological functions. Microbiology and Molecular Biology Reviews 68 320-344. (doi:10.1128/MMBR.68.2. 320-344.2004)

Sandhoff TW, Hales DB, Hales KH \& McLean MP 1998 Transcriptional regulation of the rat steroidogenic acute regulatory protein gene by steroidogenic factor 1. Endocrinology 139 4820-4831. (doi:10.1210/ endo.139.12.6345)

Shaulian E \& Karin M 2002 AP-1 as a regulator of cell life and death. Nature Cell Biology 4 E131-E136. (doi:10.1038/ncb0502-e131)

Shaywitz AJ \& Greenberg ME 1999 CREB: a stimulus-induced transcription factor activated by a diverse array of extracellular signals. Annual Review of Biochemistry 68 821-861. (doi:10.1146/annurev.biochem.68.1.821)

Soccio R \& Breslow J 2003 StAR-related transfer (START) proteins: mediators of intracellular lipid metabolism. Journal of Biological Chemistry $\mathbf{2 7 8}$ 22183-22186. (doi:10.1074/jbc.R300003200)

Soccio R, Adams R, Romanowski M, Sehayek E, Burley S \& Breslow J 2002 The cholesterol-regulated StarD4 gene encodes a StAR-related lipid transfer protein with two closely related homologues, StarD5 and StarD6. PNAS 99 6943-6948. (doi:10.1073/pnas.052143799)

Soccio R, Adams R, Maxwell K \& Breslow J 2005 Differential gene regulation of StarD4 and StarD5 cholesterol transfer proteins. Activation of StarD4 by sterol regulatory element-binding protein-2 and StarD5 by endoplasmic reticulum stress. Journal of Biological Chemistry $\mathbf{2 8 0}$ 19410-19418. (doi:10.1074/jbc.M501778200)

Stocco DM 2001 StAR protein and the regulation of steroid hormone biosynthesis. Annual Review of Physiology 63 193-213. (doi:10.1146/ annurev.physiol.63.1.193)

Stocco D \& Clark B 1996 Regulation of the acute production of steroids in steroidogenic cells. Endocrine Reviews 17 221-244. (doi:10.1210/ edrv-17-3-221)

Stocco D, Wells J \& Clark B 1993 The effects of hydrogen peroxide on steroidogenesis in mouse Leydig tumor cells. Endocrinology 133 2827-2832. (doi:10.1210/endo.133.6.8243310)

Sun Z, Shen W-J, Sucheta S-L \& Azhar S 2008 Impact of aging on cholesterol transport protein expression and steroidogenesis in rat testicular Leydig cells. Open Longevity Science 2 76-85. (doi:10.2174/1876326X00802010076)

Wang X, Diener K, Manthey C, Wang S, Rosenzweig B, Bray J, Delaney J, Cole C, Chan-Hui P, Mantlo N et al. 1997 Molecular cloning and characterization of a novel p38 mitogen-activated protein kinase. Journal of Biological Chemistry 272 23668-23674. (doi:10.1074/jbc.272. 38.23668)

Wang X, Shen C, Dyson M, Eimerl S, Orly J, Hutson J \& Stocco D 2005 Cyclooxygenase-2 regulation of the age-related decline in testosterone. Endocrinology 146 4202-4208. (doi:10.1210/en.2005-0298)

Wysk M, Yang DD, Lu H-T, Flavell RA \& Davis RJ 1999 Requirement of mitogen-activated protein kinase kinase 3 (MKK3) for tumor necrosis factor-induced cytokine expression. PNAS 96 3763-3768. (doi:10.1073/ pnas.96.7.3763)

Zaidi SK, Shen W-J \& Azhar S 2012 Impact of aging on steroid hormone biosynthesis and secretion. Open Longevity Science 6 1-30. (doi:10.2174/ 1876326X01206010001)

Zheng C, Xiang J, Hunter T \& Lin A 1999 The JNKK2-JNK1 fusion protein acts as a constitutively active c-Jun kinase that stimulates c-Jun transcription activity. Journal of Biological Chemistry 274 28966-28971. (doi:10.1074/jbc.274.41.28966)

Received in final form 26 March 2014

Accepted 22 April 2014

Accepted Preprint published online 29 April 2014 http://jme.endocrinology-journals.org DOI: 10.1530/JME-13-0287
C 2014 Society for Endocrinology Printed in Great Britain
Published by Bioscientifica Ltd. 